\title{
Containers for the Physical Internet: requirements and engineering design related to FMCG logistics
}

\author{
Christian Landschützer ${ }^{1}$ (i) $\cdot$ Florian Ehrentraut ${ }^{1} \cdot$ Dirk Jodin $^{1}$
}

Received: 29 January 2015/Accepted: 7 October 2015/Published online: 29 October 2015

(C) The Author(s) 2015. This article is published with open access at Springerlink.com

\begin{abstract}
One of the main key enablers for a successful realization of the Physical Internet (PI) scenario is a modular box that meets all requirements of an interconnected logistical network. To address all these requirements, a holistic approach including all needs of the shipping network is integrated in the methodical development process that leads to the modular box prototypes. This paper describes the methodological engineering process for the first approach to develop a modular and multifunctional load unit to implement a first real PI scenario in the fast-moving consumer goods industry. From the identified research questions, three different layers to point out in detail arise. Following the presentation of the sizing approach, engineering design is the main part. A technical view on loading PI unit loads completes this work. Several methods are applied on these different layers, and final results are presented. By highlighting the significance of technical aspects and introducing a methodological approach, the reader can pick out additional benefit from this work to use in familiar topics from engineering design in logistics.
\end{abstract}

This article is part of a focus collection on "Logistics in the Networked Industry" based on the BVL's 7th International Scientific Symposium on Logistics in Cologne in 2014.

Christian Landschützer

landschuetzer@tugraz.at

Florian Ehrentraut

florian.ehrentraut@tugraz.at

Dirk Jodin

dirk.jodin@tugraz.at

1 Institut of Logistics Engineering (Institut für Technische Logistik), Graz University of Technology (Technische Universität Graz), Inffeldgasse 25e, 8010 Graz, Austria
Keywords Physical Internet - MODULUSHCA . Modular box for fast-moving consumer goods · First physical object of the Physical Internet - Methodological engineering design process - Realization of the Physical Internet

\section{Introduction: problem definition}

Megatrends like urbanization and individualization force logistic distributors to make their business more and more efficient. They are forced to minimize the logistic costs but are facing an increasing volume of one item delivery. This is well known from the e-commerce business, and the nearly same important logistic challenge arises within the area of fast-moving consumer goods (FMCG) [1].

Despite the efforts by logistic distributors to raise efficiency in their business, logistics across the planet is societal, environmental and economically unsustainable [2]. Focussing on those challenges, the Physical Internet (PI) Initiative tries to address them as an open global logistics system founded on physical, digital and operational interconnectivity through encapsulation, interfaces and protocols. The aim of the PI is to enable an efficient and sustainable logistics web at the logistics hubs as well as at the end consumer, where current systems are not efficient enough to address the outlined megatrends [2, 3].

First steps in realizing the PI visions have been started in the project MODULUSHCA funded by the 7th Framework Programme of the European commission. Fifteen partners from research, logistics business, postal business and FMCG industry participate in this research project in close coordination with North American Partners and the international PI Initiative. This initiative represents the first genuine contribution to the development of interconnected 
logistics at the European level and provides a basis for an interconnected logistics system by 2030 [4]. More detailed information on the integrated work fields, the overall goals and the main benefits can be seen in "Appendix" (chapter 11).

The earlier-mentioned FMCG are defined as pharmaceutical, consumer electronic, personal care, household care, branded and packaged food, spirits and tobacco. Although the range of products is various, most of them share the same characteristics [5]: they are used directly by the end consumer, non-durable, sold in packaged form, are branded, at a low price with high volumes and used at least once a month (frequent purchase). The handling of FMCG in dedicated supply networks takes place in central and regional warehouses. The five main process steps within a logistics centre are the goods receipt, storing, consignment, storing again and goods issue [6]. The main tasks are supported by transportation, handling and packaging processes as well as administration processes [5].

The Institute of Logistics Engineering of Graz University of Technology is part of the MODULUSHCA consortium and responsible to develop and realize in the context of the FMCG one of the key functions of the PIthe encapsulation of products. This encapsulation is physically realized by containers developed and designed to meet the requirements from the PI and is therefore one of the key components and enablers of the PI. The following chapters will deal especially with this development and engineering design work and will reveal the first physical object of the PI: the MODULUSHCA-box (M-box). This M-box is considered as the PI container for FMCG and sets the ground for further developments in other logistics sectors.

First results of the research work on the M-box were presented previously at the 7th International Scientific Symposium on Logistics (Cologne 2014) [7, 8]. In the following work, the authors focus on describing the engineering methods used in the methodological approach to engineering design the M-box and demonstrate the progress in designing the prototype

\section{Overall goals for PI containers}

The PI Initiative tries to address the challenges and demands of the outlined megatrends (see chapter 1) as an open global logistics system founded on physical, digital and operational interconnectivity. This interconnectivity will be realized through encapsulation, interfaces and protocols. With other words [3]:

The Physical Internet is a global logistics system based on the interconnection of logistics network by a standardized set of collaboration protocols, modular containers and smart interfaces for increased efficiency and sustainability

To underline the polemic statement that today's logistics across the planet is societal, environmental and economically unsustainable, vivid symptoms for this unsustainability in logistics and therefore main challenges are provided by the PI Initiative. In order to meet this challenges, Montreuil is defining the paradigm-breaking PI vision through 13 characteristics addressing head on the grand challenge of reverting the huge unsustainability of the current way we transport, handle, store, realize, supply and use physical objects around the world [2] (presented in Table 1).

As far as the container design is concerned, four different Physical Internet Characteristics (number 1, 3, 4 and 8 from Table 1) can be identified as main development goals to be transferred to design requirements. Ballot, Montreuil and Meller further state that the PI will not handle products directly but rather the containers in which those products are packed to be transported [3]. Therefore, those containers are one of the key components and enablers of the PI. Ballot et al. [3] point out some more detailed characteristics for the containers, which can be merged with the overall development goals to identify clear design requirements:

- Unique international identification to ensure traceability, in the manner of the BIC code in the maritime sector.

- Physical protection of the content.

- Anonymization of the content.

- Standardized size.

- Standardized mechanical strength which then enables them to be handled and stacked.

- The possibility of handling and locking between containers using a standardized system, a suitable development of the twist-lock.

In physical terms, main goal in designing PI containers is to make them easy to handle, store, transport, seal, interlock, couple, load, unload, construct and dismantle [9].

In terms of the distribution system, main goals are to build unit loads out of modular containers which are then loaded on trucks in order to maximize the utilization in volume and weight $[10,11]$.

Considering the current situation in FMCG logistics (described in chapter 1), the overall goals of PI for a future interconnected, open global network and the aims of MODULUSHCA (see "Appendix"), there are three different layers of approach identified. Those three layers therefore mean three main research questions to answer in order to engineer and design a PI container: 
Table 1 Physical Internet addressing unsustainability symptoms ([2] Table 2; page 85)

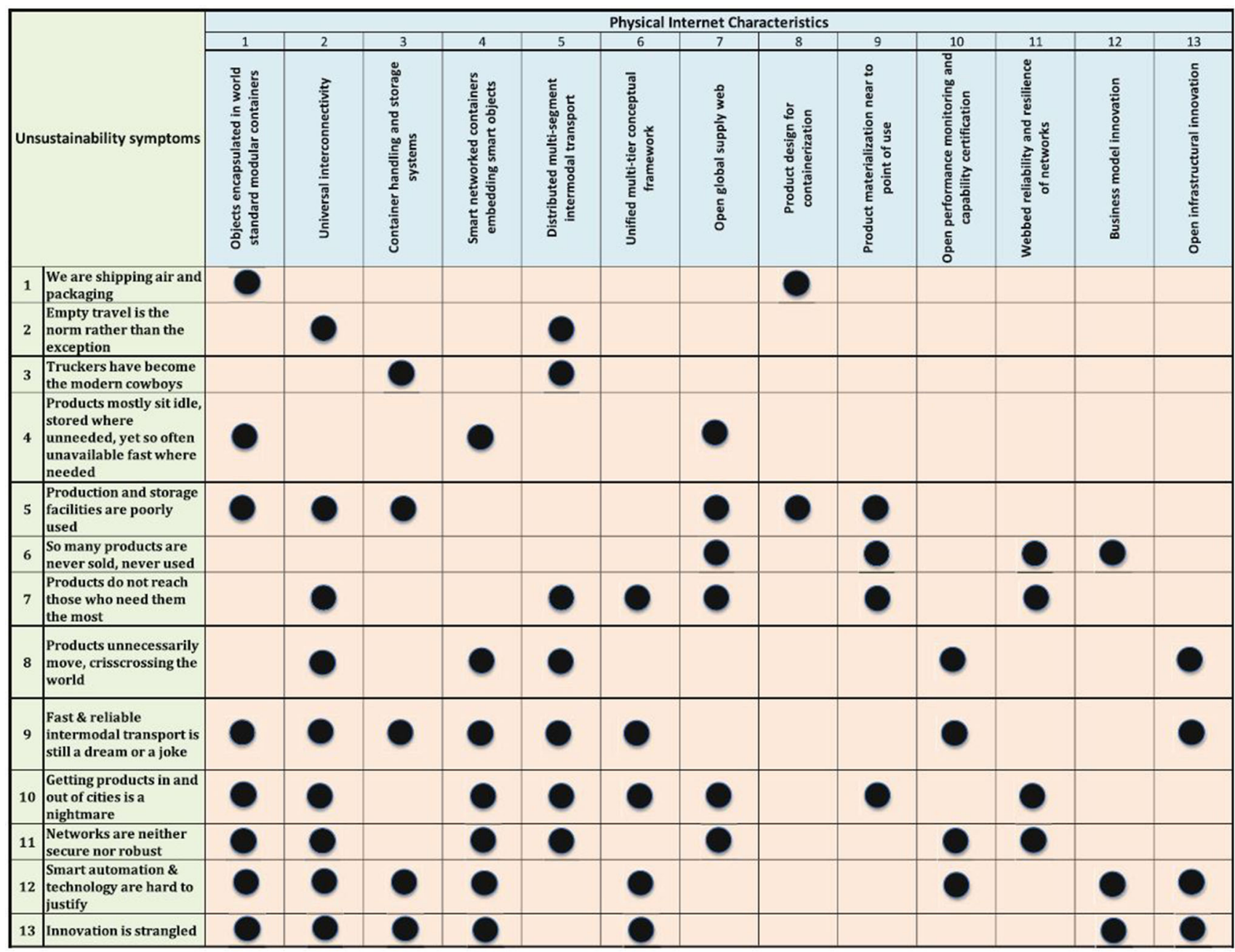

- Sizing

The inventors of the PI distinguish between three different sizes: large containers with a cross section of approximately $2.4 \mathrm{~m}$ by $2.4 \mathrm{~m}$ with a variable length, medium containers with a size around $1 \mathrm{~m}^{3}$ and small containers with a size approximately of $0.1 \mathrm{~m}^{3}$ [3]. To meet the demands of the FMCG logistics and a standardized system, the research work on the MODULUSHCA project concentrates on developing modular boxes in the magnitude of small- and medium-sized PI containers.

- Design

Uniting the requirements of the PI, the FMCG and from pooling and logistics industry leads to the requirements for the physical PI containers. These requirements can then be realized by engineering design the PI containers with computer-aided design (CAD) and computer-aided engineering (CAE) techniques.
- Loading

Changing the way actual logistic systems work will change the way of loading trucks too. In the future PI scenario, the predominant transport will be in between PI hubs [9]. Therefore, a PI-loading process within the PI logistics has to be applied.

Figure 3 highlights the difference between the situations in supply chain (SC) of FMCG today and in a future scenario of PI and assigns the three research questions in the different steps of the distribution process. Where today we pack the products in an almost infinite range of different-sized cases made of carton, in a future PI scenario, we will pack the products to a finite range of modular PI containers. These PI containers will then be combined to unit loads and shipped in an interconnected, open and global point-to-point hub network.

In the German language, the English term "container" is more commonly used to describe loading devices (see [6]). 
In order to use a consistent wording, the term M-box is introduced here. The M-box describes a special PI container developed in the MODULUSHCA project for FMCG logistics and its engineering.

\section{State of the art}

The structure of the paper follows the three-layer approach described in chapter 2 , by describing the treatment of the three different but on each other depending main research questions for developing the M-box individually.

\subsection{Current sizing methods}

During the last years, Meller has presented relevant work in defining sizes for the PI containers $[11,12]$. In this chapter, his former findings and research work as well as his findings as a member of the team from the Institute of Logistics Engineering for MODULUSHCA are presented.

In the FMCG logistics, two different trends for assigning case/box sizes to goods in general can be observed. On the one hand, there is the pragmatic way of assigning the "best-fitting" case from a given pool to the goods. Reasons to use this pragmatic way are manifold and seem convincing at first sight. There are, for example, cost savings through avoiding extensive calculations by the use of software and a high volume usage per case. In a recent paper, Meller and Kimberly presented a current scenario where the average utilization for carton boxes is $88.9 \%$ for a company using 258 different packaging cartons for 494 different products [13].

On the other hand, there are scientific approaches with methods from operational research (OR) that try to assign the best-fitting case to a given set of products. Meller states that "The problem in the literature most closely related to this approach is the container loading problem (CLP). The CLP is usually defined as arranging rectangular items in cartons with the objective to minimize the total wasted space of the cartons, subject to loading constraints [14]. As surveyed by Dyckhoff [15], the CLP is classified as the three-dimensional (3D) rectangular packing problem in the general cutting and packing problem literature" [16].

Meller states further that "There are a number of approaches for categorizing the CLP that have been discussed in the literature [17]. One approach to classify the CLP is based on carton quantity: whether packing a single carton or packing multiple cartons. Multiple cartons are necessary if a large quantity of goods need to be loaded completely [18]; on the other hand, if some goods can be left behind, only a single carton is involved in the problem [15]. The CLP can also be differentiated based on the types of items to be loaded: homogeneous items (where the items are all identical in terms of their dimensions and orientation) or heterogeneous items (where different dimensions of items are considered). Problems that fall in between these two extremes are often referred to as weakly heterogeneous cases [19]" [16].

Several papers have already examined the three-dimensional container loading problem (3D-CLP). According to Meller "Although these formulations provide valuable insight on the CLP (see [20-25]), they assumed that both a set of cartons with known dimensions and the quantities of products are given. The models then select a number of cartons to pack a given set of products. However, in this paper a model is proposed that can be used to assign a set of standard modular containers to a variety of products. In addition, the optimal quantity of items of each product to be loaded in the associated modular container is determined in the model" [16].

Meller's research, which has been reported in [11, 12], presents a modular container selection model that extends the formulations proposed by Chen et al. [22]. The problem they address was summarized as follows: "Assume that different rectangular-shaped products in the current product line need to be packed and shipped. Each product has a specific length, width, and height. Each product is currently packed in a carton with a specific length, width and height with the carton containing a specific number of items. Because in this paper M-boxes are used as our handling containers, one can assume that products are of sufficient structural integrity to allow any orientation of the items in a modular container and any packaging patterns (this is not the case with products today, which have to provide the structural integrity of the handling container today). The formulation developed and presented by Meller et al. [11, 12] assumes this as well" [16].

\subsection{Current box design}

Containers, boxes or more generally spoken loading devices and loading equipment are well treated in the literature and guidelines (see as an example [26, 27] or [28]). tenHompel [6] distinguishes, e.g. between three categories of loading equipment which are load supporting, enclosing or encapsulating.

For the M-box in the context of the FMCG, one has to distinguish between two categories of containers: the first category refers to "handling containers". Examples of handling containers today are cartons, cases, boxes and pallets. They are used to cover the product or to provide means to handle products together as a unit load. (Note that for most products today, the product itself provides the structural integrity of the handling containers, as opposed to the handling containers). The second category refers to as "transportation containers". Examples of transportation 
containers today are the international shipping container, train wagons and truck trailers used to transport handling containers. Unlike with handling containers, transportation containers must provide the structural integrity of the load and must be able to resist the elements [16].

With the advent of the PI, its inventors assume that transportation containers will remain relatively unchanged. Perhaps, over time, their dimensions will be modified so as to synchronize them over a variety of modalities (e.g. ship, ISO container, rail, truck). However, it is an assumption that in a future vision with the PI, handling containers will be reduced to modular containers and unit loads that are built out of multiple modular containers [16]. Taking now a closer look on currently used handling containers in FMCG industries, one can observe many different sizes, features and characteristics. The following categorization resumes from a comprehensive policy and market analysis as part of the MODULUSHCA project [29] (see Fig. 1). The categorization especially regards small- and medium-sized boxes (following the distinction in chapter 2).

Clustering the features and characteristics in groups of requirements linked/related together, functional groups are used to distinguish between the existing boxes. The boxes might have [29]:

- Folding/collapsible capabilities

- Stacking capabilities

- Interlocking capabilities

- Product-box interacting capabilities

- Strength capabilities

- Durability capabilities

- Cleaning capabilities

- Identification capabilities

- Handling capabilities

The comprehensive policy and market analysis shows that there are already a lot of different transport boxes on the market meeting most of the essential requirements for the PI containers. Many boxes are modular, foldable, stackable, etc., but none of them has an interlocking system meeting the demands of the PI vision.

\subsection{Current methods for loading trucks}

For shipping goods, pallets, boxes or unit loads have to be positioned on trucks. Therefore, restrictions are specified by law and guidelines (e.g. VDI $2700[30,31]$ or the Austrian KFG $\S 4$ Abs. 9a). These law and guidelines that vary from country to country describe, e.g. the maximum weight, the centre of mass, the axle load or bearing load. The technical restrictions mainly determine the maximum load a box has to withstand and the stability of the unit load. The stability of a unit load is according to BGR234 of 2006 [32] defined as the ratio between the moment of tilting which is generated by an applied force and the moment of stability. Besides further requirements result from the practical and pragmatic aspects of the packing, shipping and the loading process [33]. Examples are:

- The streets are slightly tilted to the left in order to facilitate the drain off water. Therefore, the centre of mass of the load has to be adjusted according to minimize the abrasion of tires.

- When facing icy or wet road conditions, the axle load of the driving axle should be sufficient.

As outlined before in chapter 3.1, multiple algorithms exist to solve the mixed-integer optimization problem and therefore the bin packing problem. Bin packing means assigning a given number of defined items to load units by minimizing the number of these units and is considered as a combinatorial problem. For the PI-loading process within the PI logistics (see chapter 2), this would mean to pack a defined number of unit loads on trucks in order the number

\begin{tabular}{|c|c|c|c|}
\hline \multirow{16}{*}{ 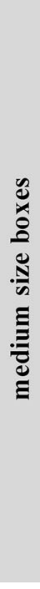 } & main function & material & additional function \\
\hline & \multirow{4}{*}{$\begin{array}{l}\text { rigid container } \\
\text { (no ISO) }\end{array}$} & plastic box & with or without top \\
\hline & & metallic box & with or without top \\
\hline & & \multirow{2}{*}{ wooden box } & fruit and vegetable box \\
\hline & & & with top \\
\hline & \multirow{3}{*}{$\begin{array}{l}\text { rigid container } \\
\text { (ISO) }\end{array}$} & \multirow{2}{*}{ plastic box } & with windows \\
\hline & & & without windos \\
\hline & & metallic box & - \\
\hline & \multirow{3}{*}{$\begin{array}{c}\text { nestable and } \\
\text { stackable box }\end{array}$} & \multirow{3}{*}{ plastic box } & 180 turn \\
\hline & & & top \\
\hline & & & arms \\
\hline & \multirow{3}{*}{ foldable box } & \multirow{2}{*}{ plastic box } & injection \\
\hline & & & extrusion \\
\hline & & cardboard box & - \\
\hline & \multirow{2}{*}{ special use } & isothermal & EPS/EPP \\
\hline & & ESD protection & - \\
\hline
\end{tabular}

Fig. 1 Clustering of the existing boxes [29]

\begin{tabular}{|c|c|c|c|}
\hline \multirow{11}{*}{ 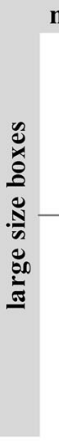 } & main function & material & additional function \\
\hline & \multirow{5}{*}{ rigid } & plastic box pallet & - \\
\hline & & \multirow{2}{*}{ wooden box } & box pallet \\
\hline & & & wooden crate \\
\hline & & \multirow{2}{*}{ metallic box } & box pallet \\
\hline & & & crate box \\
\hline & \multirow{5}{*}{ foldable } & \multirow[b]{2}{*}{ plastic box pallet } & injection \\
\hline & & & $\begin{array}{c}\text { injection - extrusion box } \\
\text { pallet }\end{array}$ \\
\hline & & wooden & foldabel pallet \\
\hline & & metallic & foldabel pallet \\
\hline & & cardboard & cardboard box pallet \\
\hline
\end{tabular}


of trucks becomes a minimum. Exact algorithms (i.e. exact branch and bound algorithm [34]) and commercially available products like [35] are currently used. As a collateral market analysis in the MODULUSHCA project shows, there are no commercial (software) products which take the law, guidelines and technical restrictions altogether into account.

\section{Identified research gaps}

To realize the vision of the PI, the fields of investigation are manifold. Comparing the overall goals for the PI containers and the derived three main research questions (described in chapter 2) with the state of the art (described in chapter 3) leads to the following research gaps (summarized in Fig. 2):

\subsection{Sizing}

In today's SC for FMCG, the diversity of brands and types of products with various sizes and weights leads to a nearly infinite range of different sizes of carton boxes. Building unit loads with such a high variance of cases is rather complicated and leads to inefficient space utilization at the pallet level and as a consequence also on a truck level. Therefore, the first problem to solve can be stated accordingly: for the FMCG market, determine the set of modular container dimensions that would balance the desire to decrease the number of options, while at the same time not overly restrict options, because to do so will result in boxes that are less full than today. In doing so with the currently outlined methods in chapter 3.1 , one has to consider that FMCG that are shipped today have specific item dimensions and are shipped in specific quantities of items per handling container.

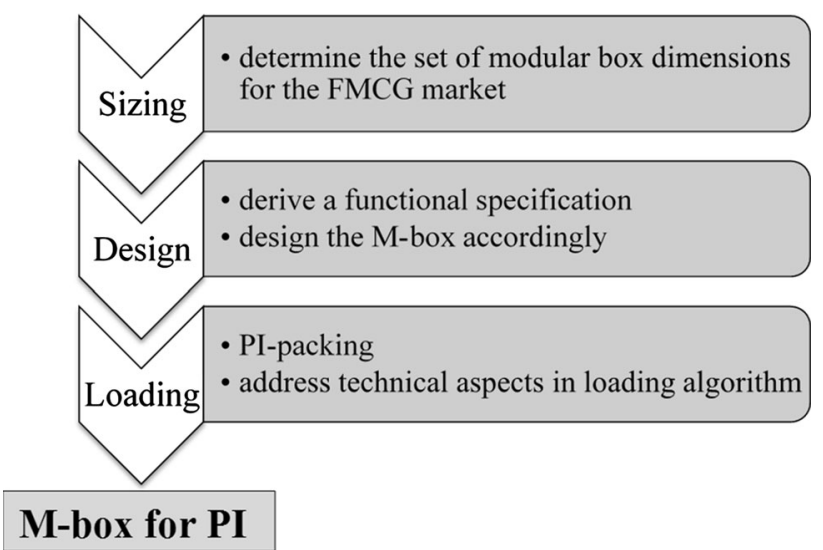

Fig. 2 Summarizing the identified research gaps

\subsection{Design}

After defining the sizes for the M-box, the next step is to develop a clear functional specification of logistics containers in FMCG logistics based on technical restrictions and box functions from SC demands. As already stated in chapter 3.2, none of the existing boxes meets the overall demands of the PI vision. Therefore, the developed functional specification forms the starting point of a methodological approach to develop, engineering design and prototype the M-box.

\subsection{Loading}

In the future PI scenario, the predominant transport will be in between PI hubs. Therefore, a PI-loading process within the PI logistics has to be applied to position the unit loads built out of M- or PI-boxes so that the number of used trailers becomes a minimum. Furthermore, there are several restrictions which are specified by law and guidelines to consider as outlined in chapter 3.3. As stated before, no commercial (software) products which take the law, guidelines and technical restrictions altogether into account exist to support the PI-loading process.

\section{Methodological approach}

Before focusing on the different methods in the three layers, a general approach has to be developed to get an honest illustration of a future PI scenario. To transfer the current situation virtually to the PI scenario, the method outlined in Fig. 3 is used.

1. Based on the shipment data of the MODULUSHCA project partner $P \& G$, trailers are identified which ship goods now. This number of trailers is the reference to compare the M-box scenario with.

2. The monthly shipped items in these trailers are identified.

3. For each of these items, the best-fitting M-box dimension out of the available sizes gets determined. The items in an M-box were $\pm 25 \%$ the number of items allowed in the current case. This process gets done with a computerized algorithm [11, 12].

4. The number and type of the used M-boxes and also their specifications like weight and centre of mass are now known. Based on these data, the unit loads can be built.

5. The stability of the unit loads is calculated to assure that the unit loads can be shipped practically. 
Fig. 3 V-model [8]

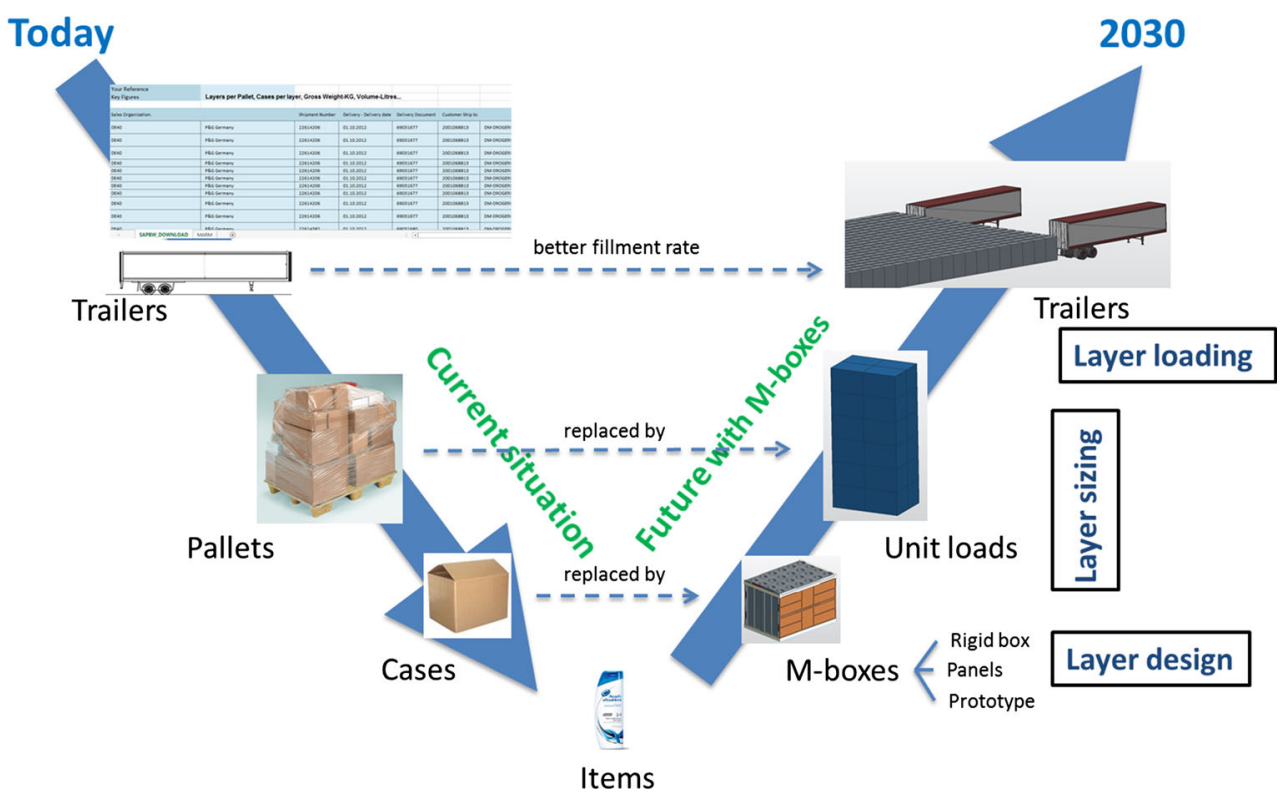

Afterwards, these unit loads get distributed to trailers to calculate the number of necessary trailers. The last step of this is to place the unit loads on the trailers so that restrictions of law (e.g. maximum and minimum axle load) and "physics" (e.g. desired centre of mass on trailer) are respected.

6. After this step, the trailers that are used in the current situation can be compared to the number of trailers in the future by using the M-boxes. Note that today trailers run from the plant to different locations. In the PI, the trailers would be shipped from the plant to a PI hub and then consolidation will be used along a pointto-point hub network.

\subsection{Used methods for sizing M-boxes}

One of the first decisions to be made in specifying a set of modular containers is the "platform" for the set. That is, if one defines the platform's width $W$, depth $D$ and height $H$, then the possible dimensions of containers that are modular to the platform can be chosen. At the outset, one considers the European trailer dimensions and the current euro pallet dimension. As the dimensions of the euro pallet are $0.8 \mathrm{~m}$ by $1.2 \mathrm{~m}$ and the inside dimensions of the Euro trailer are $2.44 \mathrm{~m}$ wide by $13.40 \mathrm{~m}$ deep by $2.5 \mathrm{~m}$ tall, the modular M-box platform can be $0.8 \mathrm{~m}(W)$ by $1.2 \mathrm{~m}(D)$ by $2.4 \mathrm{~m}$ $(H)$. Note that it is also considered a platform of $1.2 \mathrm{~m} \times 1.2 \mathrm{~m} \times 2.4 \mathrm{~m}$ and other platforms based on the international shipping container. However, such a footprint would not utilize the current European trailer as well as the rectangular $0.8 \mathrm{~m} \times 1.2 \mathrm{~m}$ footprint. To further refine this, all three dimensions $(0.8,1.2$ and $2.4 \mathrm{~m})$ are divided by 1 ,
$2,3, \ldots$, as long as the result was greater than or equal to $0.1 \mathrm{~m}$. These dimensions would be considered exterior dimension standards. Then, based on many discussions, all combinations of $x, y, z$ that were not integer at the mm level (that is, eliminating an $x$ value of $266.7 \mathrm{~mm}$ formed by dividing $W$ by 3 because 266.7 is not an integer) were eliminated, including a few other values (e.g. $y=150 \mathrm{~mm}$, and $z=160,150 \mathrm{~mm}$ ). The reduced set of modular container dimensions is presented in Fig. 4 [16].

With this platform presented in Fig. 4, the total possible number of M-boxes would be 440 . These 440 different sizes of boxes can be considered to be a platform for further development and as a starting point for the recommended set of pooled containers. They are recommended by the MODULUSHCA consortium to maintain container fullness as much as possible and to improve overall utilization at the unit load level. However, decisions around final platform selection will be iterative, subject to cost, industry and retailer support and also subject to the future development of the products in the FMCG industry. Moreover, in addition to the benefits of a modular platform, there are benefits that can result if a small number of dimension combinations are in use in an asset pooling arrangement.

\subsection{Used methods for the M-box design}

To get aware of the relevant steps in the engineering design process of the M-box, it is necessary to introduce the methodology. For the M-box development and design process, the systematic approach of VDI 2221 [36] and VDI 2222 [37] is used. This systematic approach deals 
Fig. 4 Modular platform with 440 different M-box dimensions [16]

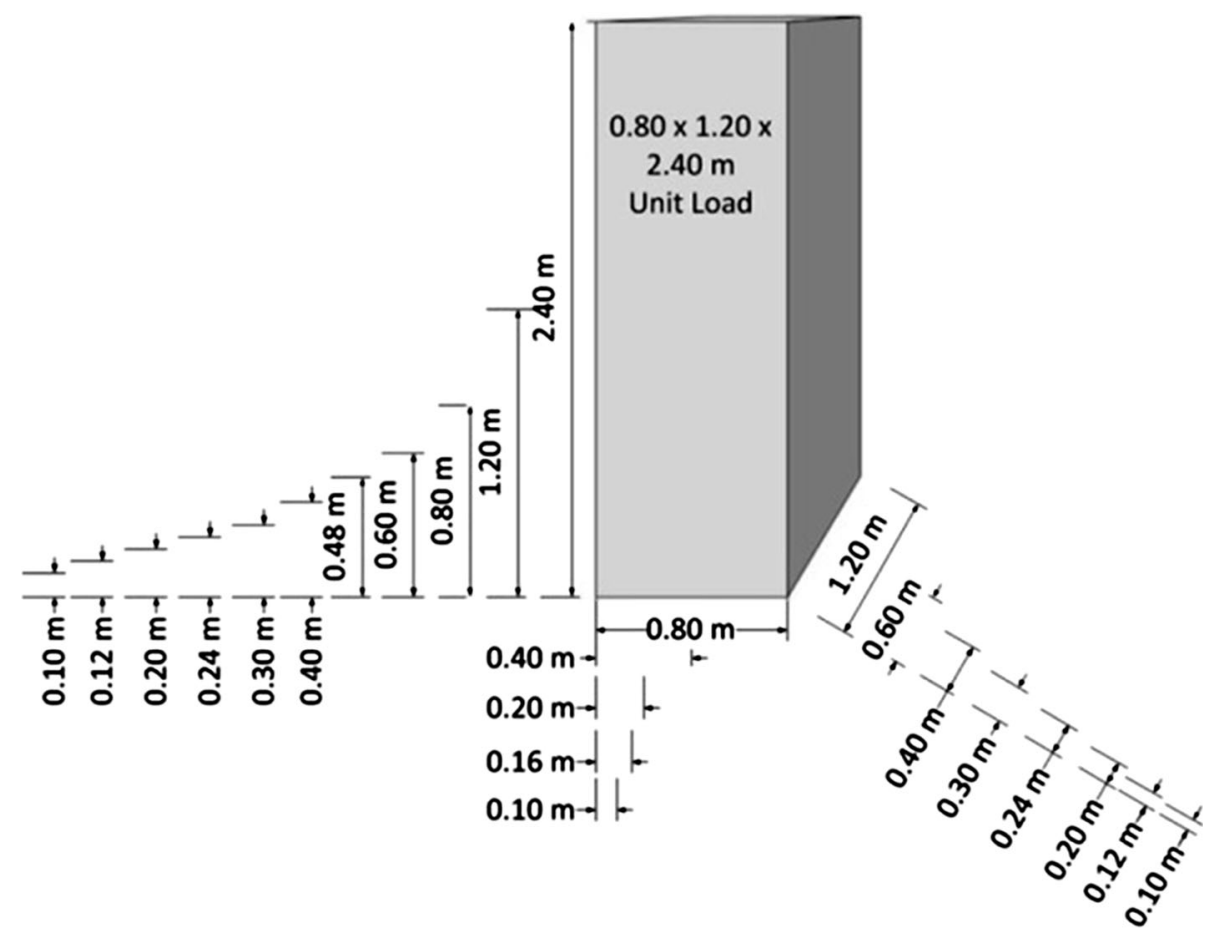

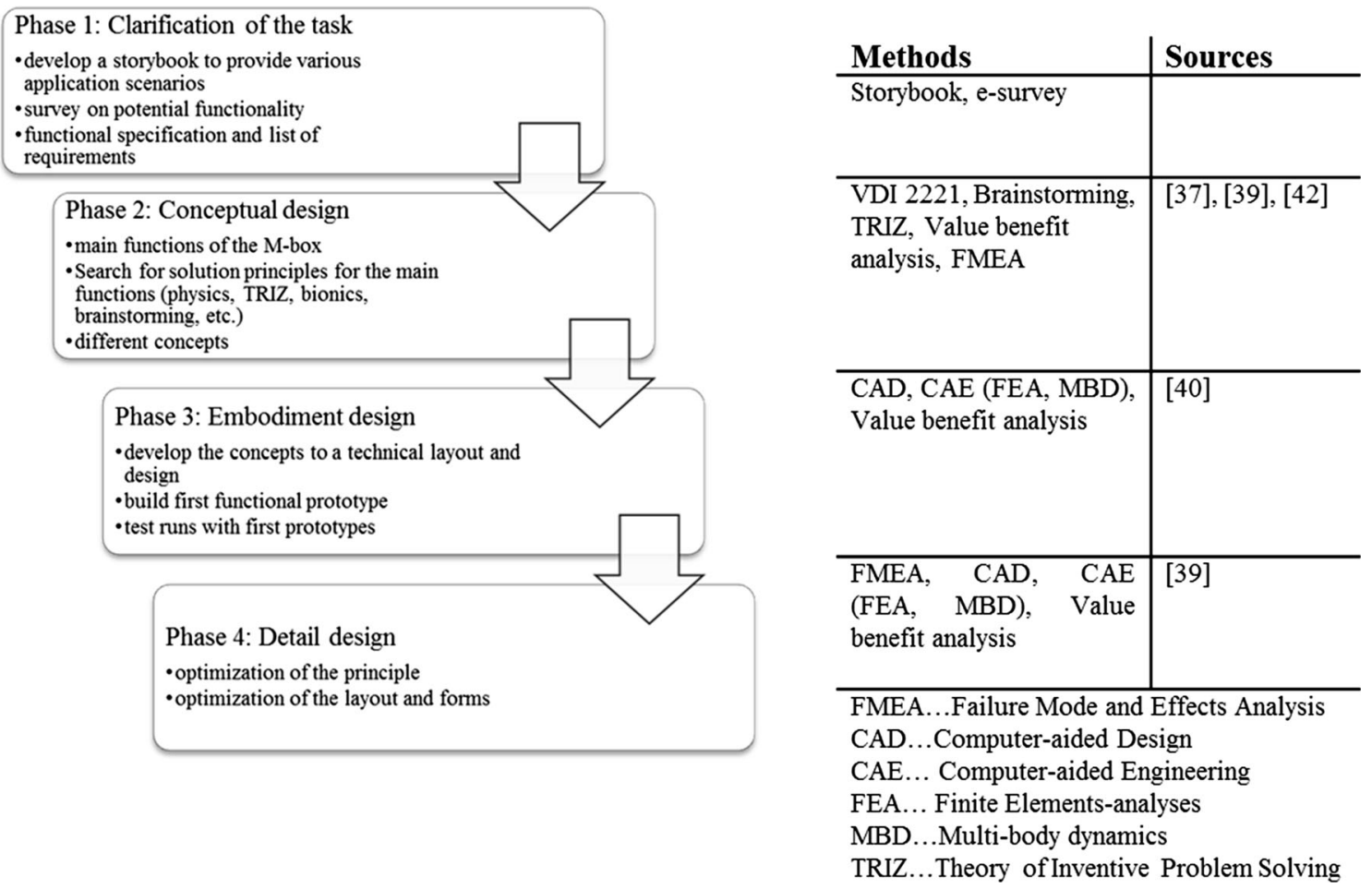

Fig. 5 Different phases of the VDI 2222 applied to the development process for the M-box design, oriented on [37]

with the universal and non-sector-specific principles of the methodological engineering design and defines process steps after a common logic and practicality. Through a systematic and methodological approach, the often random outcomes of an engineering design process are based on arguments and hence easy to compare, measure and lead to results more quickly. The process is divided in four different phases, and Fig. 5 shows the different phases applied on the development process for the M-box design. 
A top-down design approach using CAD is chosen [38], because the modular boxes are geometrically familiar. This enables, by less change management effort, an efficient design of not only one M-box but the whole set of modular boxes up to the suggested 440 different sizes (Fig. 4).

A key enabler of this work is to develop a functional specification for the modular units. To do this requires a better understanding of cross-industry and sector views, of the type of functionality that is desirable. Insight into what traits are considered most important via appropriate stakeholder input enables identification and prioritization of potential design features. In order to capture as many of stakeholder views as possible from which to define the suite of functionality requirements, an e-survey is used to solicit input. The survey is based on a map of "typical" SC interactions between manufacturing sites, distribution centres, co-packing sites and retail outlets. These SC interactions are based on scenarios provided by a storybook approach (a particular example is outlined in Fig. 6) which is a pragmatic way to bring experts in logistics and experts in engineering into line. This approach focuses on particular aspects of the SC and on five focus areas [16]:

- Reuse

- Repair
- Recycle

- Reach (also beyond EU)

- Ergonomics

The aim of this is to raise key questions around what the M-boxes should look like, how they may work and better understand how people should interact with them.

\subsection{Used methods for loading M-boxes}

Functions that are mainly influenced by the logistics processes (packing, loading and shipping) are identified by MODULUSHCA scenario simulations [39]. Therefore, two relevant "logistic processes" are identified which are important for the box functionality and mainly influenced by technical restriction:

1. Building unit loads out of M-boxes.

2. Allocation of the unit loads on the trailer.

A limiting constraint for this first realization is that each unit load is built out of M-boxes of the same size that are filled with the same product. This leads to the fact that for each type of M-box, the packing pattern for the unit load is previously fixed. So it is necessary to control if the unit load fulfils all restrictions of law and if it fulfils all

A ) M-box is stored somewhere
at a distribution centre
The M-box is stored on the floor of a
backyard of a small DC in Finland. To
save space the M-box is folded and
piled up with other M-boxes.
G) M-box is handled \& shipped
to distribution centre

The M-boxes are loaded onto a truck while empty and folded and then shipped to a large distribution centre. They are taken out of the truck and then stored by an automatic system.

B) M-box is moved to a picking
station
One of the picking places runs out of
M-boxes. A Modulushca lifting truck
moves several M-boxes from one
stored stack towards the picking
area. The driver misjudges the
distance to the M-box and knocks
into the pile. After lifting the boxes,
he drives to the picking station via
several turns and drives over
bumpers.

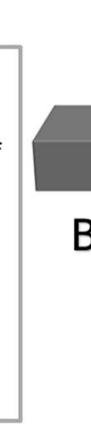

A C) M-box is filled with items of product

A worker lifts the M-box up to a table and unfolds it. He starts to fill the Mbox with bottles of shower gel, but drops one bottle. The gel pollutes the inside of the M-box. The worker removes the polluted box to get it cleaned and starts to fill the products into another M-box.
D) M-box is handled \& prepared for shipping

After the items are stored in the $M$ box, the identification object is programmed and as a backup the box is marked with an identification card. Afterwards the worker closes the top of the box and moves it to the truck where 2 different boxes are combined in order to handle them as one unit. On the way to the truck the worker slips and smashes the M-box to the floor.
F) M-box is handled \& the items removed from the M-box

In the large Spanish city the M-boxes are taken out of the truck with the help of a fork lift. In the small German city the M-boxes are taken out by a worker and placed in a roll cage. After the items are removed from the M-boxes, they are folded and stored somewhere.
E) M-box is transported to a retailer

The M-boxes are loaded into a truck, some of them are only $51 \%$ full. Two different $\mathrm{M}$-boxes are combined in order to handle them as one unit.

The destination of the M-boxes are a small city in Germany and a large city in Spain.

Fig. 6 Storybook to sketch SC interactions for the survey [16] 
Fig. 7 Process of packing, loading and shipping analysis [33]

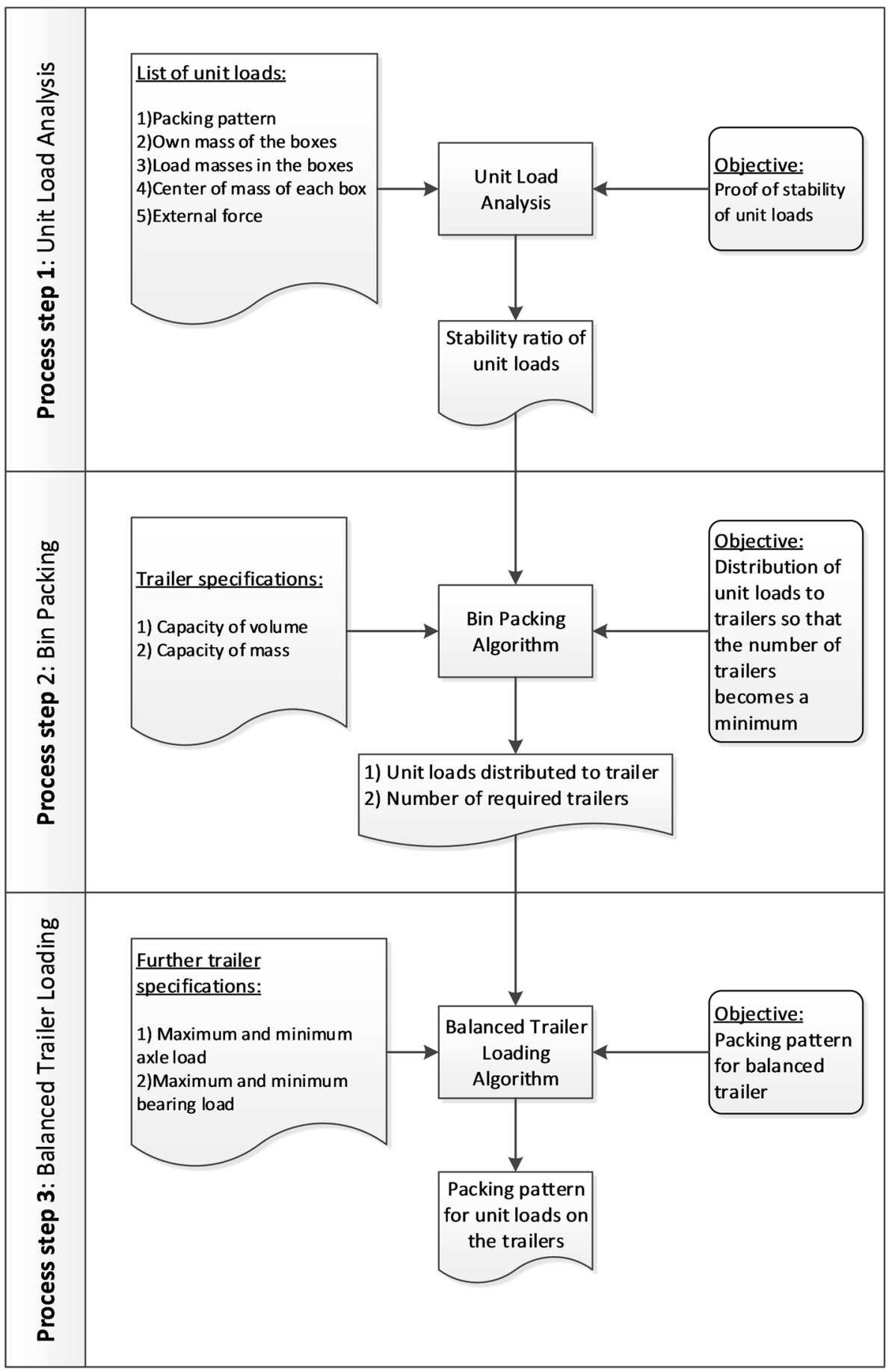

technical specifications to be shipped. To meet technical restrictions for the complete shipping process, a bin packing algorithm and an algorithm to position the different unit loads on a truck are used [16, 33].

One of the major points for the unit load analysis (process step 1 in Fig. 7) is the stability of the unit load which is important for the M-box design. Therefore, the packing pattern of the unit load is analysed by taking into account the position of each M-box in the unit load, net weight of the boxes, payload in the boxes, centre of mass of each box and a potential applied external force. The result of this calculation is a ratio $S$, which is built by the moment of stability divided by the tilting moment (see Fig. 8). Due to the fact that all M-boxes are interlocked, the unit load can be seen as one unit and the calculation guideline from BGR234 of 2006 [32] can be adapted to the equation described in Fig. 8. Additional loads from transportation dynamics, as outlined in [30], are not subject of this consideration. 
Fig. 8 Forces on unit load and stability [8]

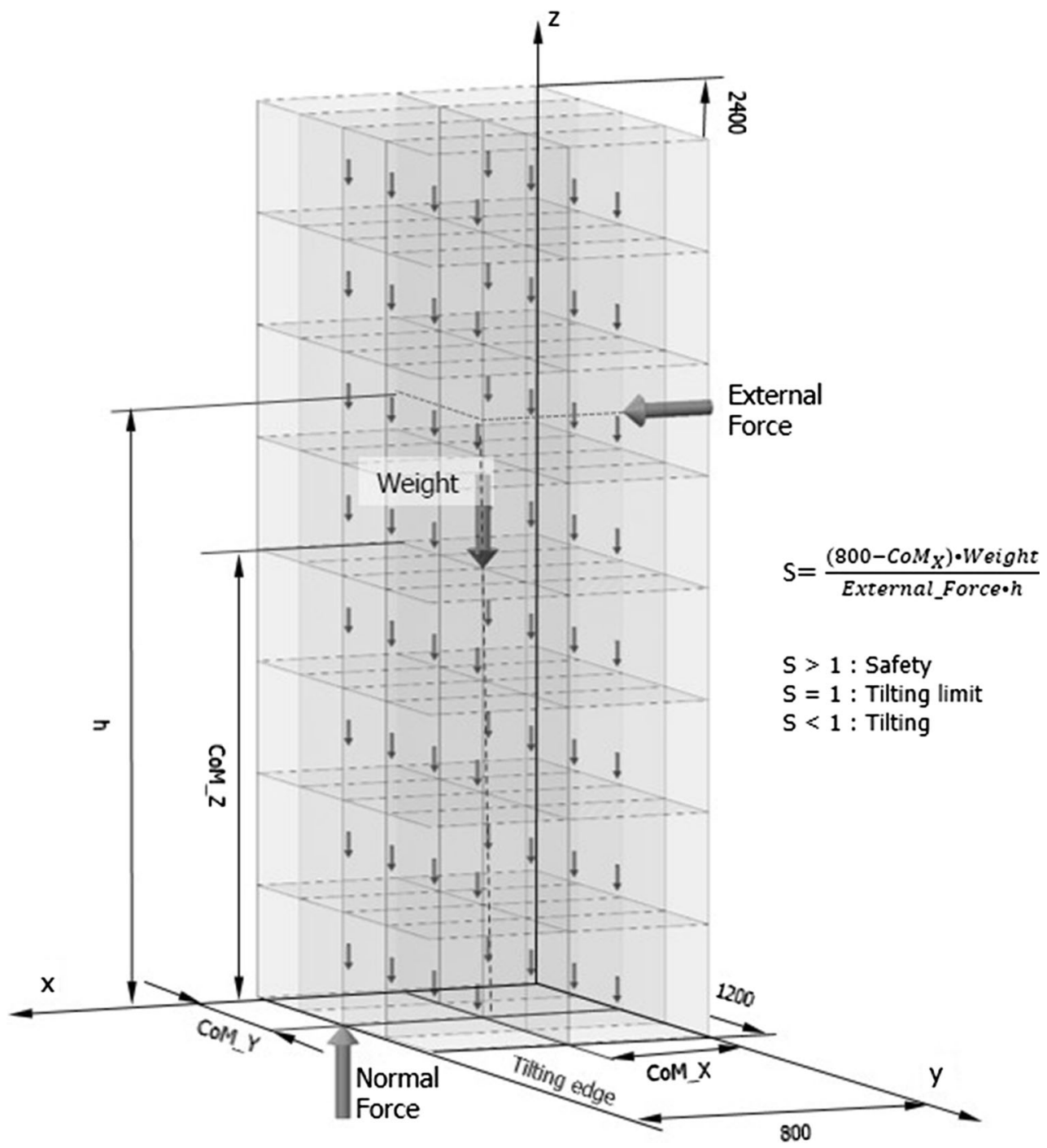

To ship the unit loads, they have to be positioned on trailers. Based on the facts that the number of possibilities to position the $\mathrm{n}$ unit loads increases with $n$ ! and the problem is NP complete [34], the second logistic process "Allocation of the unit loads on the trailer" was split up in two sub-processes (process step 2 and 3 in Fig. 7). The first sub-process distributes the unit loads to trailers so that the number of trailers becomes a minimum. In literature, this is also known as "2D-vector packing". The second sub-process places the unit loads on the trailer on their precise position in a way that the common requirements (described in chapter 3.3) like maximum and minimum axle load or bearing load of the trailer are fulfilled.

As pointed out in chapter 1 , the main focus of this document is on the engineering design of the M-box. The detailed mathematical description behind the used methods for loading the M-boxes can be seen in $[8,33]$.

\section{Findings and results}

\subsection{Results for sizing M-boxes}

A test scenario data set of 1186 different products, all currently shipped by the consortium member $P \& G$, is used to calculate the optimum set of M-boxes for this particular data set. This diverse and representative portfolio is used to drive the optimization and efficient trailer loading by considering mixed unit loads. In order to develop an affordable and effective solution for MODULUSHCA that can be implemented in the FMCG market and adequately leverage the benefits of pooling, only five (5) different sizes of the M-box are presented as a first step in Table 2 (shown as outer M-box dimensions). These five different sizes can be considered as a recommendation for a future build, still keeping in mind that engineering issues that will have an 
Table 2 Proposed outer dimensions for the M-box [8]

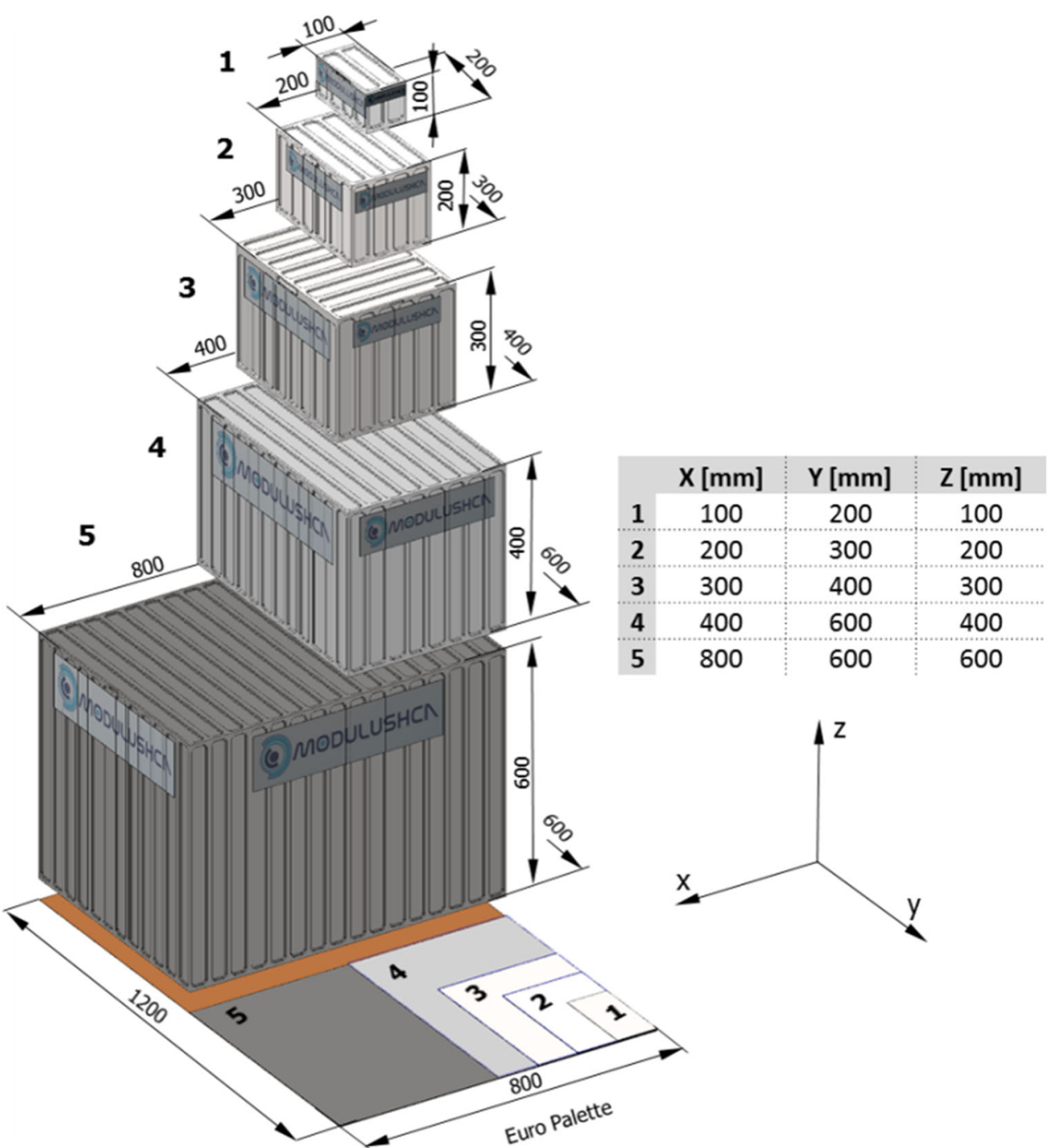

impact on the sizes and shape of the M-box will be addressed and resolved in the design stage. Furthermore, the test runs with the prototypes within the scope of the MODULUSHCA project and the lessons learned from it will also have influence on the final set of M-boxes (more than five sizes can be included).

While this selection is not directly modular with each other, they are with the modular platform $(1.2 \mathrm{~m} \times 0.8 \mathrm{~m} \times 2.4 \mathrm{~m})$ presented in chapter 5.1 (Fig. 4). Moreover, it is still possible to build loads as long as they are modular to the unit load level and additionally it is possible to build unit loads on a different unit load platform. The five sizes chosen are still compatible to the needs of a modern pooling business model. A future option is to build the boxes not as a rigid box but out of panels. This means that a panel can be used as a side panel, bottom panel or top panel and allows building many different box sizes out of less different panels (see chapter 7). For the MODULUSHCA project, the consortium decided to put the focus on rigid boxes which are compatible with today's SC systems. In order to show how a future scenario can look like the innovative idea of panels will be further developed.

To identify the impact of a future PI scenario and to highlight the difference in performance to the current situation (using cardboards and pallets), the general approach which is described in chapter 5 (Fig. 3) is used. For each of the items in the test scenario, the best-fitting M-box dimension out of the available sizes gets determined (note that not all available sizes have to be chosen for the given set of items). This process is done with a computerized algorithm from literature as described in chapter 3.1. The results of the test scenario are presented in Table 3 .

As the results of the test scenario show the truck fullness, M-box utilization depends strongly on the number of used box sizes. This leads to the fact that the number of used trailers significantly decreases (about $22 \%$ ) with the full set of used M-boxes but increases by using only five 
different box sizes. Modelling the key performance indicators (KPI) and solutions for operational interconnectivity in FMCG logistics has shown that the whole SC must be taken into account and that handling costs are the major part of logistics costs. The use of M-boxes is then very useful for reducing handling costs and a more efficient way to ship goods. The cost impacts, benefits or on-costs of the M-box solutions will be driven not only by improvements enabled by better vehicle utilization, but also by improvements in unit, case and load handling efficiency and physical storage [39] (further information on costbenefits see [39]).
Besides the impact of a future PI scenario, the results of the test scenario illustrate the dilemma in the current logistics system based on carton-based containments where the product is required to provide much of the structural integrity of the unit load. Actually, nearly full carton cases of products (above $85 \%$ with nearly unlimited range of carton case sizes) lead to only $70 \%$ full unit loads, because stacking carton boxes does not allow same maximum heights than M-boxes. This instance and the derived requirements of the SC lead to the results summarized in Table 3. These $81 \%$ full unit loads, with a much smaller number of box sizes than actual carton case sizes, can be

Table 3 Truck fullness results [29]

\begin{tabular}{llllll}
\hline & $\begin{array}{l}\text { Item utilization of the } \\
\text { M-box's volume (\%) }\end{array}$ & $\begin{array}{l}\text { M-box utilization of the unit } \\
\text { loads volume }(\%)\end{array}$ & $\begin{array}{l}\text { Item utilization of the } \\
\text { unit load (\%) }\end{array}$ & $\begin{array}{l}\text { Number of } \\
\text { trailers used }\end{array}$ & $\begin{array}{l}\text { Difference to the } \\
\text { current situation }(\%)\end{array}$ \\
\hline Five M-boxes & 56 & 100 & 56 & 745 & 5 \\
Nine M-boxes & 63 & 100 & 63 & 652 & -8 \\
$\begin{array}{l}\text { Full set (155 } \\
\text { out of 440) }\end{array}$ & 100 & 81 & 549 & -22.5 \\
\hline
\end{tabular}

Fig. 9 Key functions of the M-box [8]

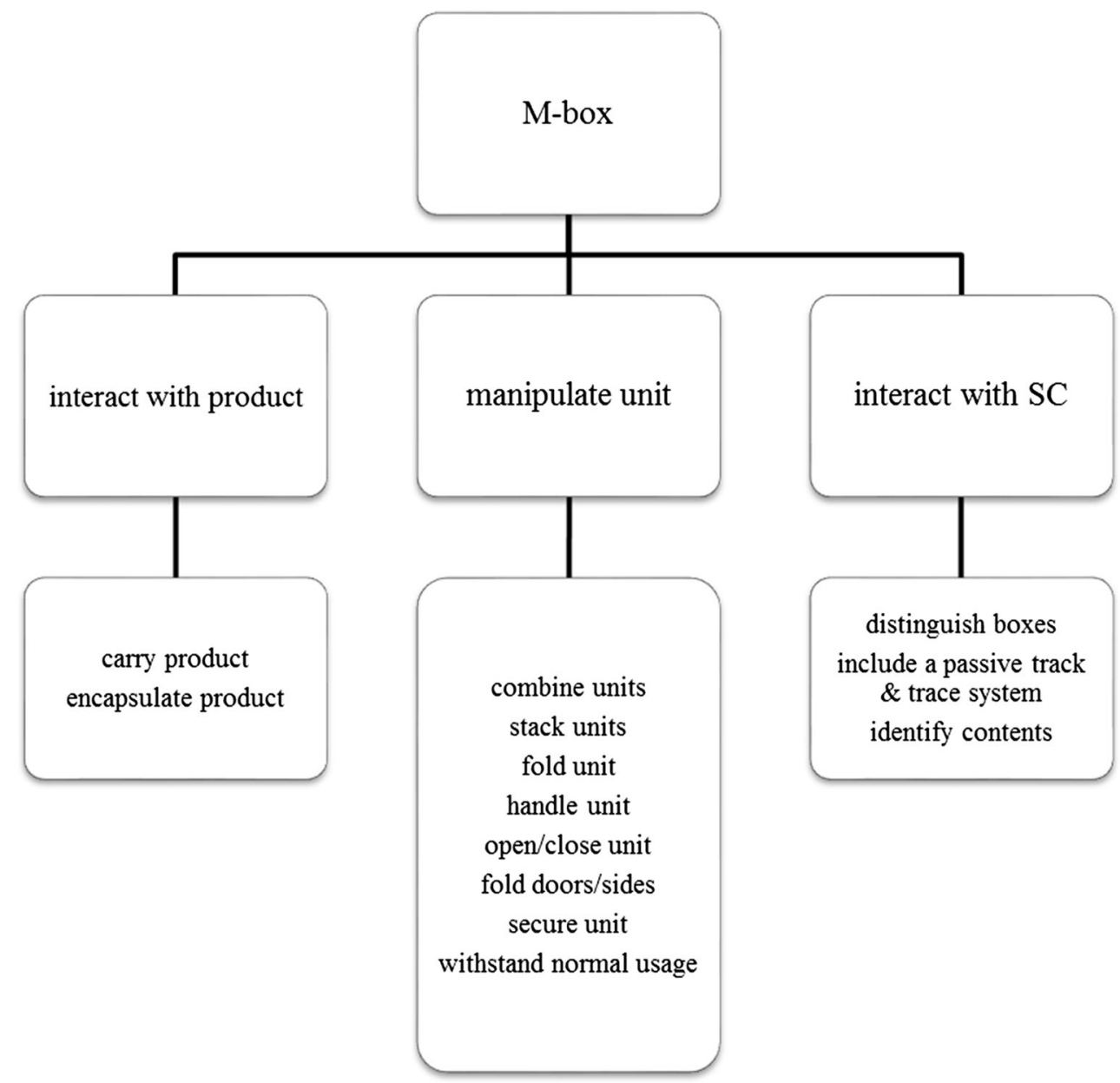


seen as an achievement of the whole MODULUSHCA idea, besides $22,5 \%$ less trailers.

\subsection{Results for the M-box design}

A key enabler of this work is to develop a functional specification for the modular units. The first step of the presented methodology is the clarification of the task (see Fig. 5). As described in chapter 5.2, an e-survey based on scenarios provided by a storybook approach is used to identify and prioritize potential design features for the M-box. The result of the survey is to define "must have", "nice to have" and "not required" functionality characteristic. The must have characteristics are then used to derive the main functions of the M-box and also requirements for the design. These functions for the M-box used in the PI vision are clustered to main functions and are listed below in Fig. 9.

Following the different phases of the VDI 2222 [37] (as described in Fig. 5), the next development phase is conceptual design. Since conceptual design uses the methodological approach of VDI 2221 [36], the starting point is to investigate different physical effects to find possible solutions principles for each of the key functions. To further assess the different principles and to focus further developing work on the most promising solution, they are evaluated following the methodology of Pahl/Beitz [40] by different criteria:

- Compliance with the overall task

- Fulfils demand of the specification

- Realizable in principles

- Within permissible costs

- Incorporates direct safety measures

- Preferred by designer's company

In the next steps, developing tools like the TRIZ method [41] and brainstorming in a larger team helped to find more detailed solutions to realize the functions. The developed solutions for each of the key functions are then summarized

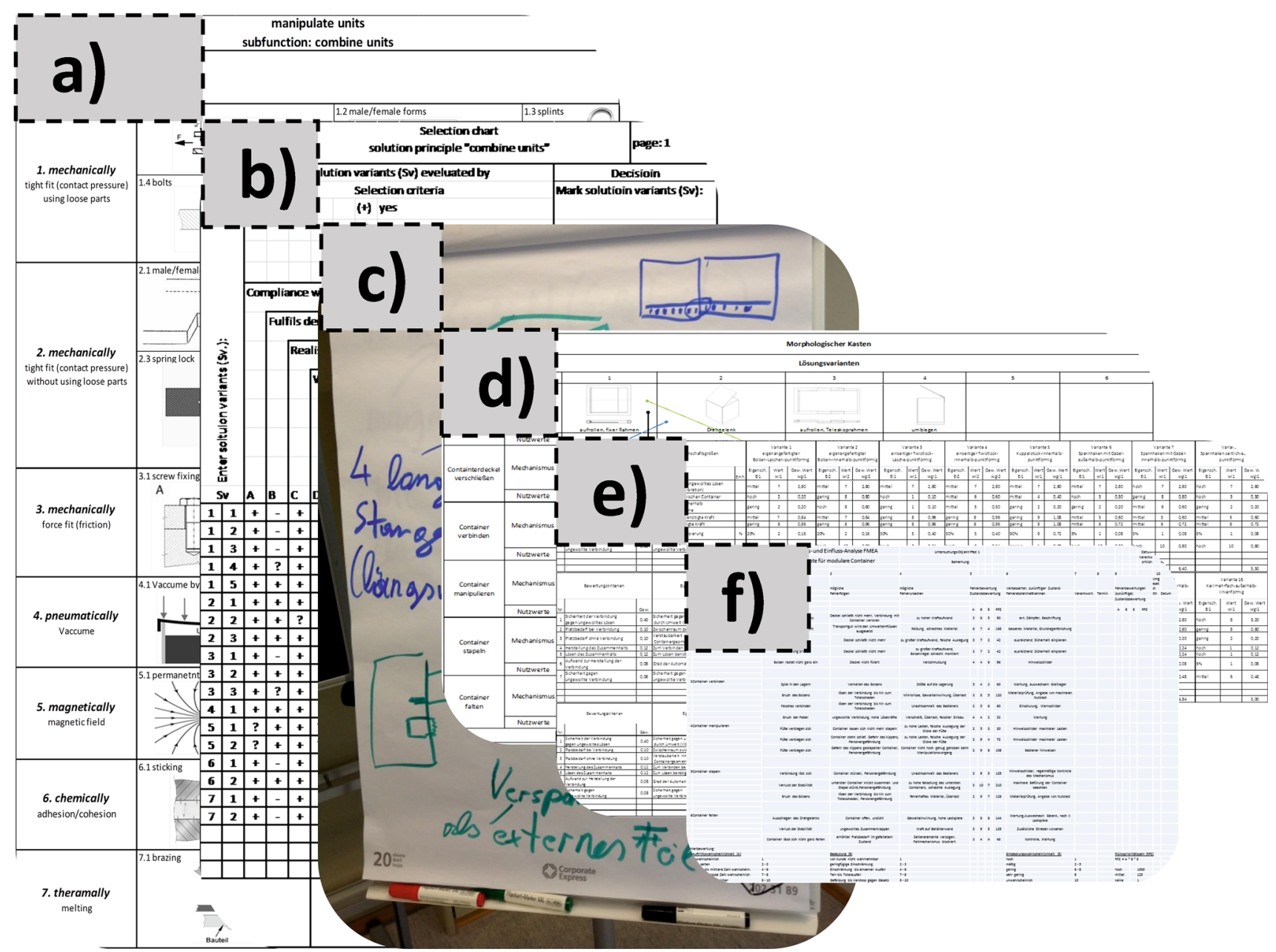

Fig. 10 Different steps in the conceptual design: a finding solution principles; $\mathbf{b}$ assessment of the solution principles according to Pahl/ Beitz [40]; c developing solutions through TRIZ and brainstorming; d morphological box with different solution variations; $\mathbf{e}$ value benefit analysis and techno-economical analysis [44]; f FMEA 
in a so-called morphological box (also known as "Zwicky box"), and different solution variations for the M-box design are selected. Before deciding on the first

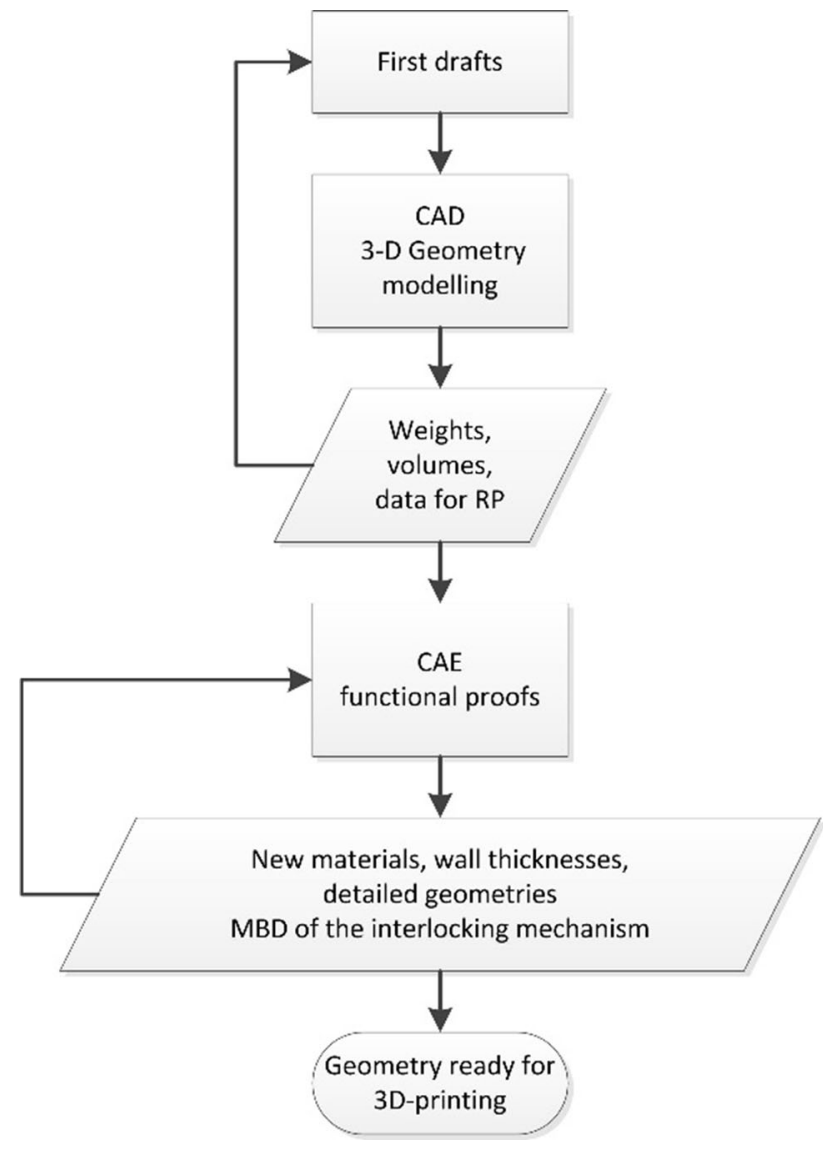

Fig. 11 Virtual development process and engineering tools [8]

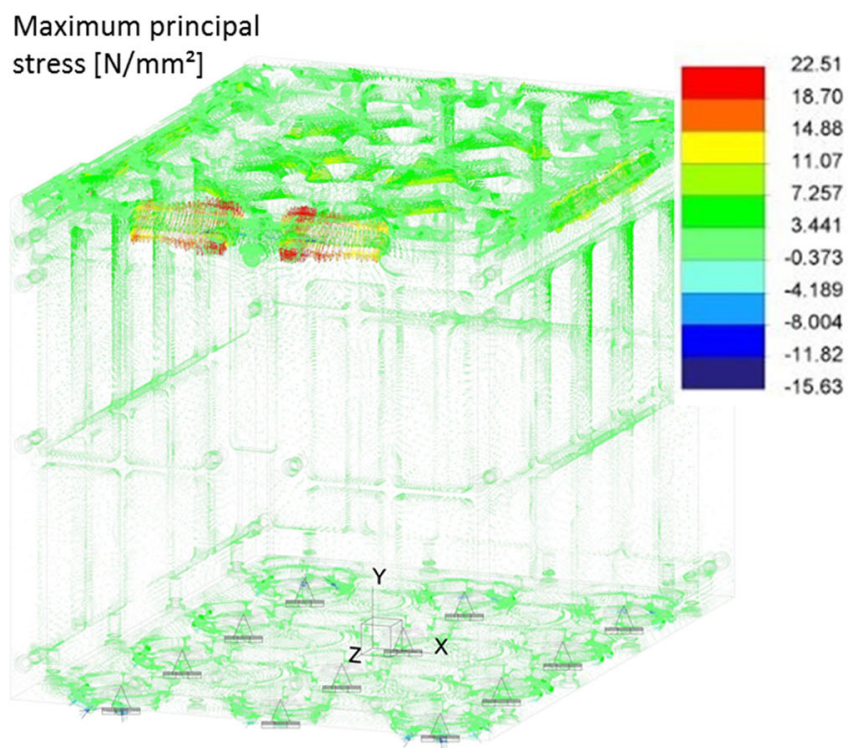

embodiment design to be realized, the selected solution variations are assessed with a value benefit analysis and a failure mode and effect analysis (FMEA). The different steps of these design phases are briefly shown in Fig. 10. More details can be seen in [16, 29].

As outlined in chapter 3.2, there are already a lot of different transport boxes on the market meeting most of the essential requirements for the PI containers. Many boxes are modular, foldable, stackable, etc., but none of them has an interlocking system meeting the demands of the PI vision. Therefore, the MODULUSHCA consortium decided to further focus on the development of the interlocking mechanism to pave the way for the realization of the PI. For the innovative interlocking mechanism, a male/female system situated on top and at the bottom of each box is chosen, due to comprehensive and broad assessment results.

Steps 3 and 4 of the methodology presented in Fig. 5 are embodiment design and detail design. Therefore, various virtual methods like CAD and CAE support the methodical engineering process (shown in Fig. 11).

During this virtual development process, iteration take place after each important development step. Structural analysis with finite element methods (FEM and FEA) and multi-body dynamics (MBD) calculations is used to model and simulate the behaviour of the M-box virtually. After the first development step, the structural strength of the M-box is proofed via FEA (see Fig. 12). This provides decisions about the material choices and other design details to guarantee the required stiffness and strength of the M-box. In engineering, the proposed 3D-printing material is roughly new and crucial FEA with CAE provides valuable insights and a more streamlined design

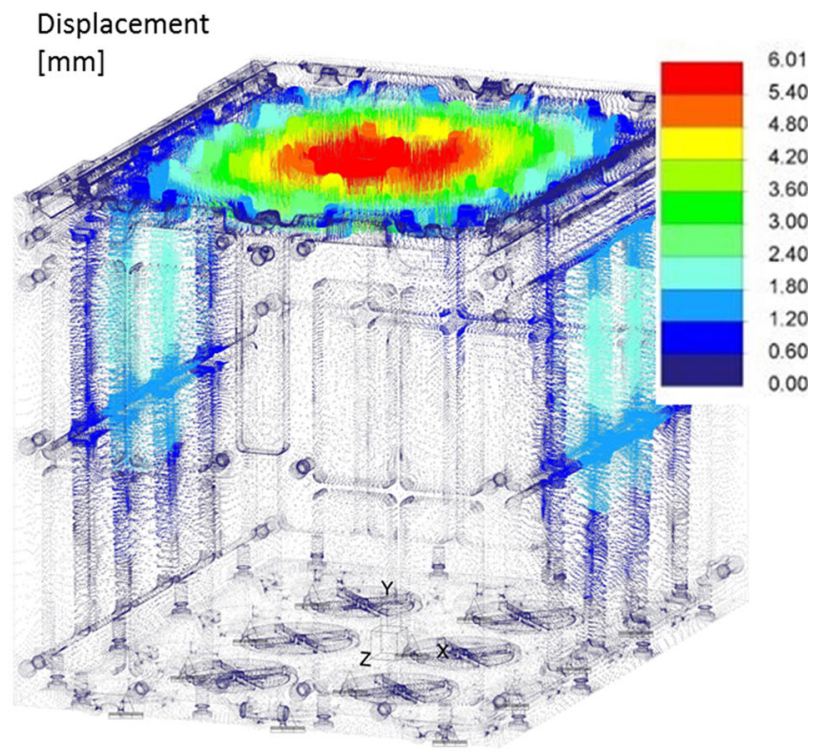

Fig. 12 Results of M-box's FEA [42] 
process than laboratory testing in this early stage. The presented results in Fig. 12 show the maximum principal stress and displacement of the M-box prototype in a virtual test scenario in which the lowest box of a unit load is charged. The force applied in FEA corresponds to average loading density of $500 \mathrm{~kg} / \mathrm{m}^{3}$ (note that according to the BGR234 of 2006 [32], a safety factor of 2 has to be taken into account) and depicts that the material choices and design details are suitable to cope with the maximum load as required in the test scenario. Further details can be seen in [42].

For the interlocking mechanism, multi-body dynamics analyses are carried out to calculate the load on specific components of the mechanism in different scenarios during its lifetime. This step is necessary to reach adequate dimensioning of the design parts according to the appearing loads. This leads to minimization of space, secure operation and reduction in wear.

In order to proof the PI scenario (further described in chapter 7), the MODULUSHCA consortium decided to prototype several M-boxes in two different sizes (see KPIs in Table 4). After several iterations in the design process (see also [29]), the drafts are evolved to first prototype design as seen in Fig. 13.

To proof the PI scenario, the focus of the first prototype is on how to combine the units with the interlocking mechanism. Therefore, it does not fulfil all the functions

Table 4 KPIs of the M-box prototypes

\begin{tabular}{lll}
\hline & Small M-box & Large M-box \\
\hline Outer dimensions $(\mathrm{mm})$ & $300 \times 400 \times 300$ & $400 \times 600 \times 400$ \\
Inner dimensions $(\mathrm{mm})$ & $270 \times 360 \times 275$ & $370 \times 560 \times 375$ \\
Volume usage $(\%)$ & 74.25 & 80.94 \\
Weight $(\mathrm{kg})$ & 2.9 & 5.7 \\
\hline
\end{tabular}

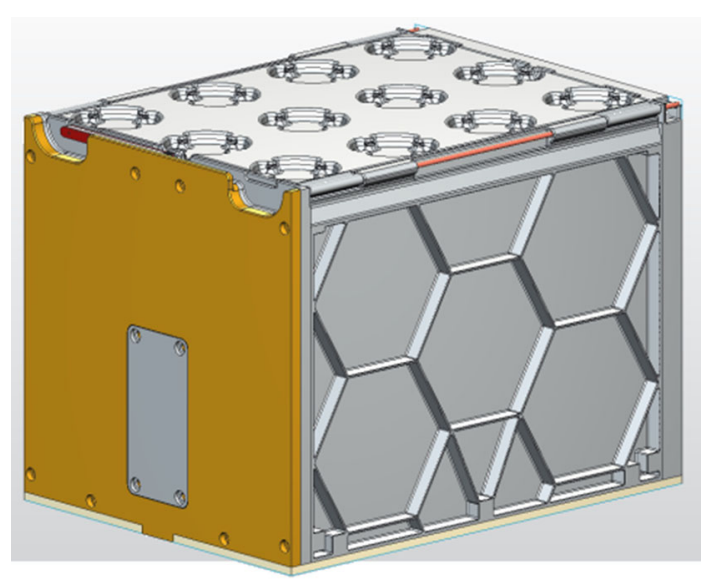

Fig. 13 Small M-box prototype design in CAD and requirements presented in Fig. 9. As already stated before, the innovative interlocking mechanism is realized with a male/female system situated on top and at the bottom of each box. To build a unit load, the different M-boxes have to be positioned on top of each other in a criss-cross packing pattern. To activate or deactivate the interlocking mechanism, the lever (see detail B in Fig. 14) that is positioned at the top of the M-box has to be turned. Turning this lever drives a sliding sheet positioned in the double floor of the M-box (see detail C in Fig. 14) via a rope/cable which operates in one of the side wall. The translational movement of the sliding plate is then converted to a rotational movement of rotating plates positioned underneath. If one M-box is positioned on top of another, the rotating plates then gear into the top panel of the M-box underneath. The rotating plates are positioned in a modular distance of $100 \mathrm{~mm}$ which allows the M-boxes to overlap, the building of unit loads with different-sized M-boxes and turning the M-boxes by $90^{\circ}$. Using a handle which is positioned at the top of the M-box to activate or deactivate the interlocking mechanism is on the one hand a matter of safety and on the other hand a matter of accessibility. If one M-box is positioned on top of another, the mechanism cannot be deactivated by accident and is selfsecured. As the FMEA points out, the accidentally unlocking of connected boxes is a severe injury risk. Therefore, the lever is either always covered by a box on top or can be fixed if there is no box on top and thus always secured. On the other hand, if one M-box is positioned in the middle of the top layer of a unit load, it is still possible to access the handle in contrary if the handle would be positioned at the bottom of the M-box. Further details can be seen in [29].

The developed mechanism and the current manual movement to interconnect the M-boxes can be seen as the basis for future developments to integrate the M-boxes in fully automated supply chains. For future use, the mechanical system "handle-rope-sliding plate" can be replaced by automated actuators which establish the interconnection by rotating the discs to interlock the units. With an appropriate energy supply and intelligence, the M-box will then be able to navigate autonomously through future PI-supply networks. A survey on ergonomics and handling capabilities which was part of the MODULUSHCA project revealed that a M-box without additional handles could cause problems. Lifting the box by grasping the structure on the side panels will lead to direct pressure on the nerves and/or blood vessels of the fingertips. This increases the risk of discomfort and injury. Furthermore, the survey pointed out that positioning the handles on the long side of the box would be disadvantageous. In order to keep the centre of gravity closer to the body, the handles ought to be positioned on the short side 

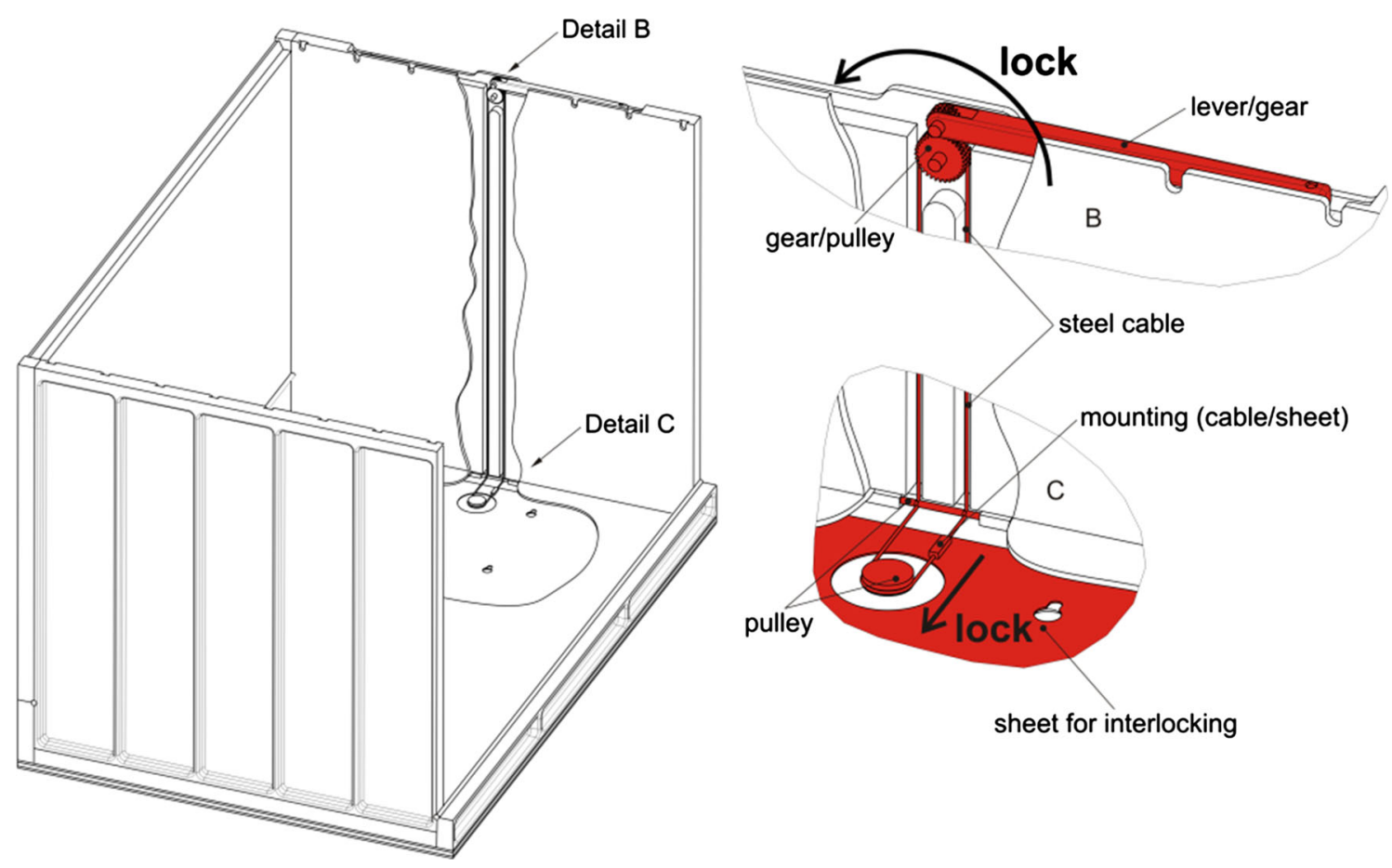

Fig. 14 Interlocking mechanism of the M-box

of the box (the one housing the interlocking mechanism). In order to solve these problems and assure a handling of the boxes which meets the demands of ergonomics, additional handles are proposed (see [42]). They can be positioned on top of the M-boxes (like any other M-box) and use the same principles to interlock as it was explained early in this section (rotating plates gear into the top panel of the M-box).

In order to establish a starting point for functional tests and design evolution, the prototypes are produced with the 3D printing technology stereolithography (STL) [43] (see Figs. 15, 16). The KPIs for the produced prototypes are described in Table 4.

The next step in a future design process would be to improve the design according to functional test results. One major step is to increase the volume usage up to a range of $80 \%$ for the small M-box and $85 \%$ for the large M-box. Furthermore, the design ought to include more functions like a possibility to identify the content, access to the products not only from the top but also from the nonfunctional side panels, ways to secure the M-box and better ergonomic handling which are core functions of the whole PI idea (see Fig. 9).

\subsection{Results for loading M-boxes}

The aim of the methodology described in chapter 5.3 is to allocate the unit loads built out of M-boxes on each single trailer on their specific position. Therefore, two relevant

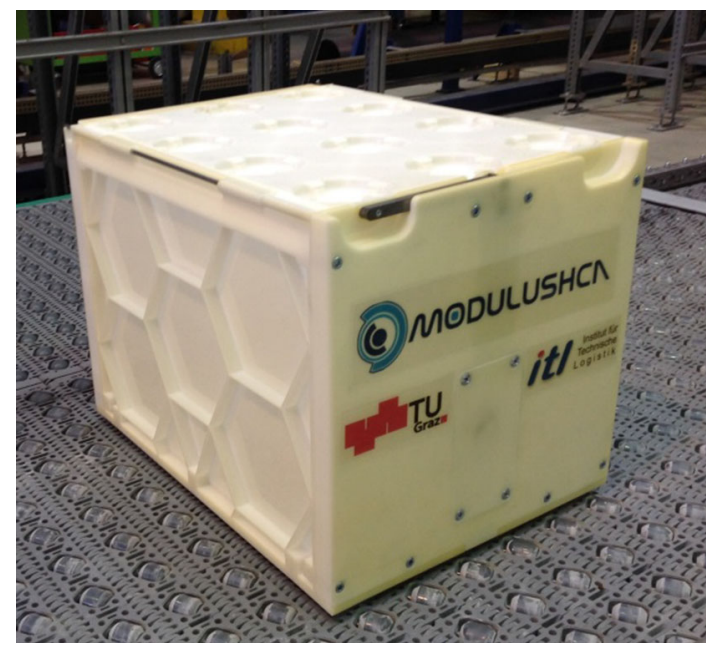

Fig. 15 Physical prototype of the small M-box

"logistic processes" in the PI packing are identified which are important for the box functionality and mainly influenced by technical restriction:

1. Building unit loads out of M-boxes.

2. Allocation of the unit loads on the trailer.

These logistic processes are part of the general approach to identify the overall impact of a future PI scenario which is described in chapter 5 (Fig. 3). Therefore, the difference in performance to the current situation using cardboards and pallets can be seen in Sect. 6.1, Table 3. 
As a showcase example, a typical European trailer and data based on the findings in the sizing process (see chapter 6.1) are used. The restriction of law by the road traffic act in Germany and further technical restrictions defining the boundaries outlined in Sect. 3.3 are considered in this example. Figure 17 shows a significant result of the algorithm and depicts the boundaries, centre of mass, axle load and bearing load. The different columns refer to the weight of a unit load placed on a specific position.

\section{Conclusion and outlook}

The PI aims to bring maximum flexibility and interconnectivity to the SC, and the M-boxes are a key element of this intention. Starting the design process, it was obvious

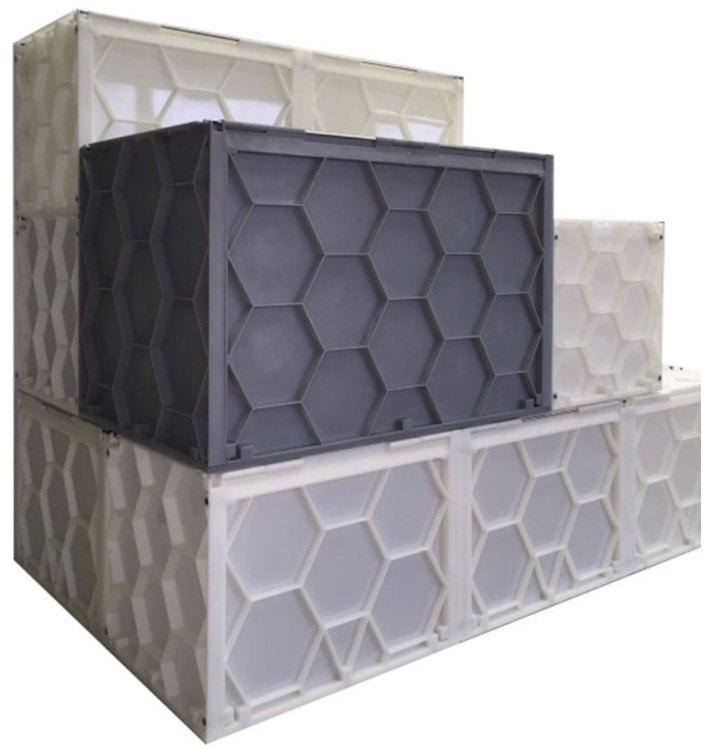

Fig. 16 Interlocked part of a unit load comprising small and large M-box prototypes that the gap between the SC in the PI vision and the SC system today will lead to two fundamentally different ways to build and design a modular box (see chapter 6.2):

1. Rigid boxes - as described in chapter 6.2

2. Boxes built out of panels:

Panels mean modular panels which can be used as a top panel, bottom panel or side panel with no limitation to orientation. Using such modular panels will allow building many different boxes and using less different panels (an example is outlined in Fig. 18) and as a consequence will bring more flexibility to the SC system.

This future scenario, allowing many different rigid boxes or detachable boxes built out of panels in the SCs, can raise doubts about the efficiency and feasibility of pooling so many different boxes or parts and can lead to logistical and financial problems and obstacles. Challenges to overcome will be:

- In the complexities of the modern SC keeping components together will be a huge logistical challenge.

- As soon as a part of a product is detached, it is at a risk of being lost and also damaged.

- A successful pooling business is based on having the right product available at the right location at the right time.

- One way to overcome this would be to budget the additional costs in oversupplying the network to overcome the risk of component shortage.

As the PI Initiative and the MODULUSHCA concept aim to change the whole SC and the way it works, the consortium strongly believes that these obstacles are manageable in the future. Therefore, a future task within the MODULUSHCA project will be to further develop the innovative concept of modular boxes built out of modular panels and to proof the overall assumptions of the PI with real "physical" test runs.

\section{Weight distribution $x-y-z$}

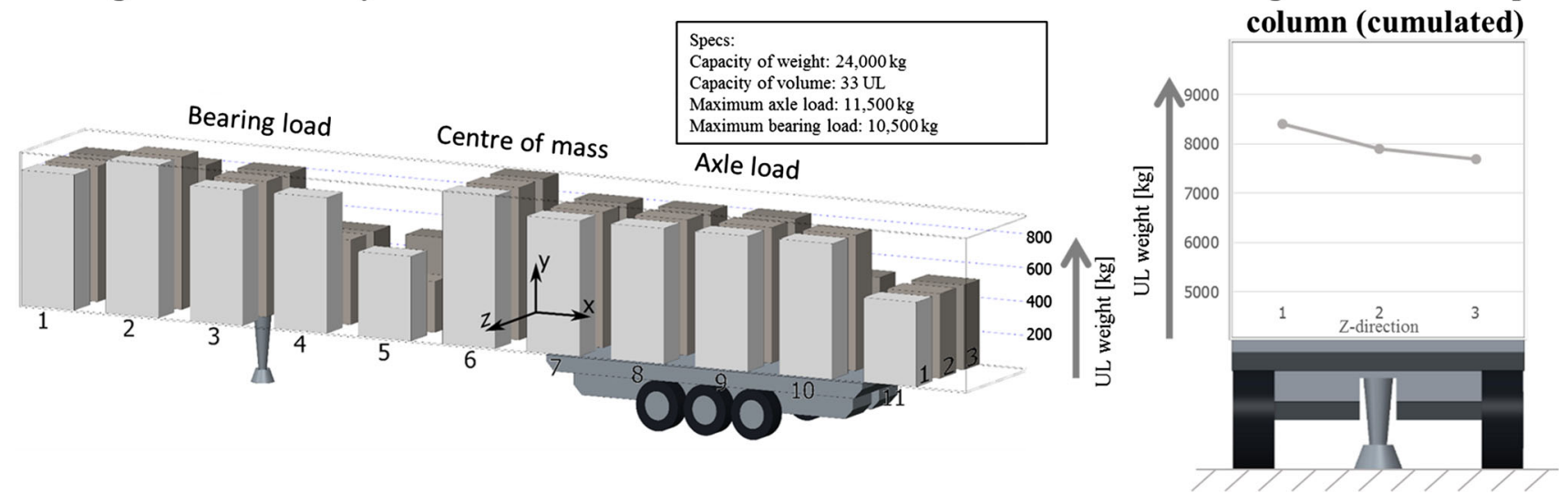

Fig. 17 Balanced trailer loading [8] 
(a)

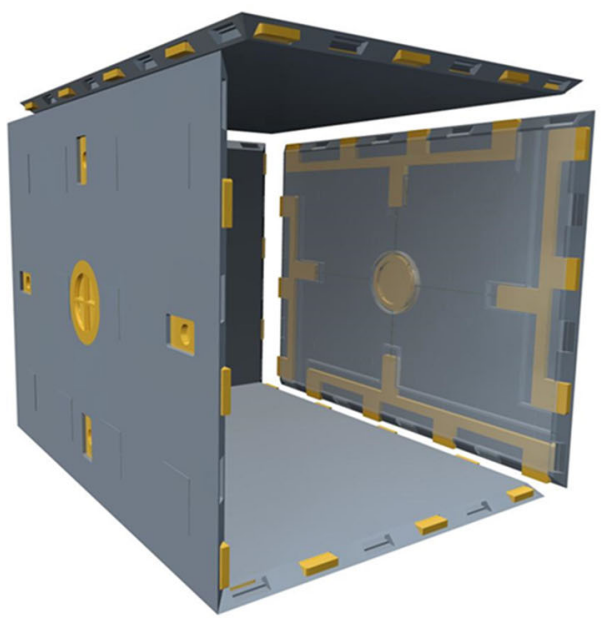

(c)

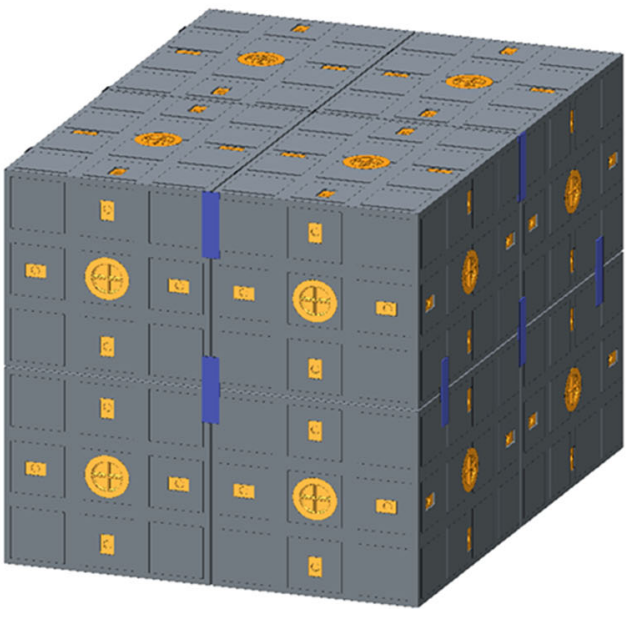

(b)

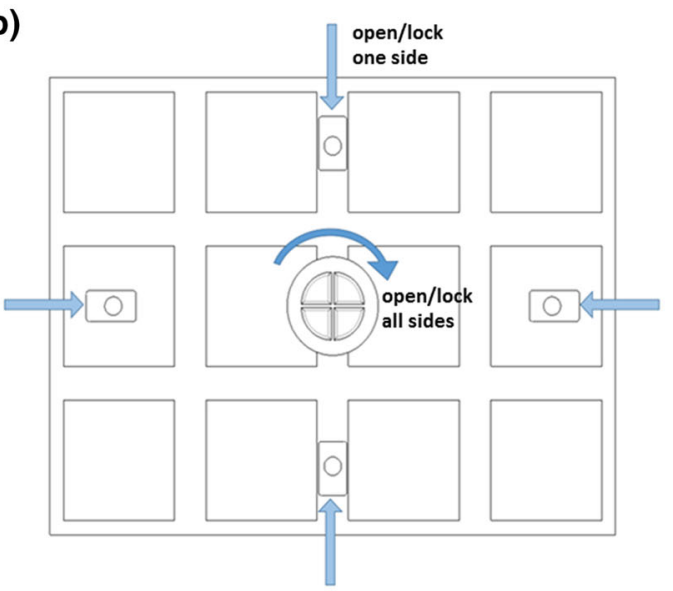

(d)

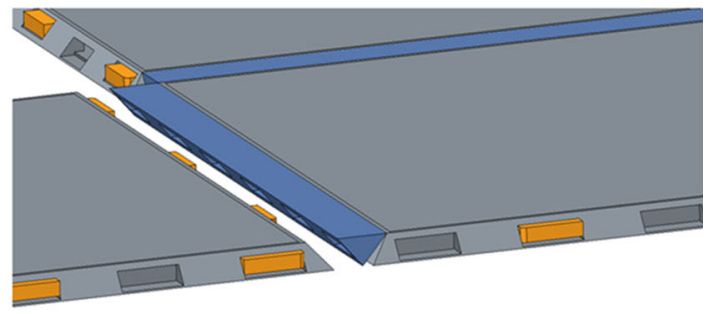

Fig. 18 M-box built out of modular panels [42]: a first prototype design; b panel-panel-locking system actuation; c M-boxes built out of panels interlocked with additional connectors; $\mathbf{d}$ planar-locked panels in order to form a larger panel

The first "physical" test run of MODULUSHCA will take place in a closed inter-site SC of one of the consortium partner's customization centre. In this first logistics pilot, the developed M-boxes will replace pallets and cases that are currently used for the intra-/inter-site transportation. The aim is to scale this up to an open interconnected network beyond the company boundaries at later stage accomplishing the scope of this project. The pilot will consist on introducing some M-boxes into the current flow of goods of a company evaluating and monitoring the impact that the new system will have on people's safety, product security (decreased damage and traceability), processes and information flows. The M-boxes will be assessed against the following KPIs:

- Ergonomics (weight, grip handle)

- Quality assurance (cleanability, package and product damage)

- Safety (fire protection)

- Others and should demonstrate value creation capabilities. An inter-site transportation pilot will be performed in order to validate vehicle loading optimization, stackability, stability, 24" drop test, shaker table, inclined conveyor or even ISTA 3E standard for shipping of full product pallets.

The second "physical" test run will use one of the consortium partner's distribution networks. It will demonstrate the handling of the new information formats as well as analyse the handling M-boxes in the transhipment processes, together with testing the sensor system and communication device (not part of this article, see [4]) that will be developed. The demonstration will make an effort to integrate and test the algorithm about collaborative scheduling and routing for interconnected logistics. These tests use an existing physical and/or digital infrastructure of a logistics service provider. Special interest will be the operational fulfilment of the reversed logistics (empty packaging and returned goods) during normal deliveries. Optimizations in combining reversed logistics with operational deliveries could prove efficient deployment of the 
modular container. This will be performed in order to validate the KPIs of handling, (un)loading, reversed logistics, traceability, utilization of truck capacity, stackability and robustness.

Initially, the project group expects increased load efficiency thanks to the interconnectibility of the M-boxes, allowing better space utilization in storage and in transport. Once the M-boxes will become a standard, there will be even more efficiencies as the FMCG companies will naturally converge towards products and packages designs that maximize the weight and volume fill of the boxes themselves. The main benefits out of the test runs in a closed inter-site SC demonstration and in distribution networks are:

- Greatly reduced amount of carton versus what is in use today

- Increased load efficiency

- Improved both safety and security issues all along the $\mathrm{SC}$

- Increase in load efficiency; use of available box/trailer capacity

- Overall decrease in the transport kilometres and reduction of $\mathrm{CO}_{2}$

- Improved handling during loading and unloading

- Reversed logistics versus operational deliveries

- Traceability

Besides all necessary OR and logistic considerations within the PI idea, this work shows obviously that engineering design and "physical objects" are essential contributors to the overall goals identified.

The methodological and creative development of 3Dprinted prototypes brought valuable insight in design, handling and identified further research questions. Besides the scientific approach in box design, the economic and cost-efficient production in larger quantities is a major challenge for the loading device industry. Despite using completely different product methods in the future production of the M-boxes, the presented findings in engineering design regarding the different aspects (the three layers) can be reused efficiently.

\footnotetext{
Acknowledgments Numerous researches have supported and encouraged the authors in developing the described M-box through rigorous comments and stimulating discussions. Many thanks to all of them: from the Physical Internet Initiative, Benoit Montreuil from Georgia Institute of Technology, Eric Ballot from Mines ParisTech and Russell D. Meller from TU Graz and now Fortna; from the MODULUSHCA consortium, Marcel Huschebeck from PTV, James Spanton from CHEP, Sergio Barbarino from P\&G, Juan Alcaraz from ITENE and all the other members of the consortium; from the Institute of Logistics Engineering of Graz University of Technology, Andreas Wolfschluckner, Thomas Stöhr and all other colleges. The research leading to these results has received funding from the European Union Seventh Framework Programme under the Grant Agreement 314468
}

Open Access This article is distributed under the terms of the Creative Commons Attribution 4.0 International License (http://crea tivecommons.org/licenses/by/4.0/), which permits unrestricted use, distribution, and reproduction in any medium, provided you give appropriate credit to the original author(s) and the source, provide a link to the Creative Commons license, and indicate if changes were made.

\section{Appendix}

MODULUSHCA (modular logistics units in shared comodal networks) tries to make major contributes by introducing the Physical Internet (PI) to FMCG logistics. The main goal of MODULUSHCA is to provide solutions for better space usage and standardization as well as to provide interchange scenarios and technology for shipping goods between continents. It is a 3-year research project with 15 partners from research, logistics and postal business and FMCG industry. Its objective is to achieve the first genuine contribution to the development of a much more efficient logistics, an interconnected logistics at the European level, in close coordination with North American partners and the international PI Initiative. The goal of the project is to enable operations with newly developed ISO modular logistics units of sizes adequate for real modal and co-modal flows of FMCGs, providing a basis for an interconnected logistics system seeking a significant twodigit improvement in operations' efficiency.

MODULUSHCA integrates five interrelated working fields [4]:

1. Developing a vision addressing the user needs for interconnected logistics in the FMCG domain;

2. Developing a set of exchangeable (ISO) modular logistics units providing building blocks for larger units;

3. Establishing digital interconnectivity of the units;

4. Developing an interconnected logistics operations platform leading to a significant reduction in costs and $\mathrm{CO}_{2}$ emissions;

5. Demonstrating the exploitation of the modular logistics units and of the interconnected platform in two implementation pilots for interconnected solutions.

The overall goals are [5]:

- To set the landscape by elaborating the PI-enabled interconnected logistics vision and by developing and demonstrating core components of this vision.

- To achieve both a simulation-based and a field-based proof of concept by gradually implementing and testing key functions of interconnected logistics and involving key stakeholder groups through all development and implementation phases. 
- To ensure a global synchronization with concurrent projects in the USA and Canada within the international PI Initiative and pave the way for a common and early market implementation at the intercontinental level.

The main benefits after the 3-year research period will be (started October 2012):

- Demonstrate the technical, digital and operational feasibility of seamless handling of cargo within SC operations across companies and transport modes.

- Recommending industry standards for ISO modular logistics units to be deployed along the entire SC of different branches for a European wide and global market introduction.

- Develop models to assess the SC benefits providing a methodology for cross-process and cross-company SC analysis for industry and policy makers.

- A clear information handling approach, including data consistency and transport monitoring along the journey as model contributing to extend and enhance standardization developments in eFreight and iCargo.

- Developing optimization algorithms for loading capacity optimization and scheduling transferring especially to SME user groups.

- Enhance the innovation process at the interface material and transport flow to stimulate a gradual market take up and implementation process.

- Stimulate the market uptake of new interconnected logistics systems and other innovations developed and tested within the project and thereby increasing the viability of the implementation.

\section{References}

1. Meller RD (2012) The Physical Internet. Logistikwerkstatt Graz, Graz

2. Montreuil B (2011) Towards a Physical Internet: meeting the global logistics sustainability grand challenge. Logist Res. doi:10. 10007/d12159-011-0045-x

3. Ballot E, Montreuil B, Meller RD (2014) The Physical Internetthe network of logistics networks. La documemtation Francaise/ Predit, Paris

4. MODULUSHCA (2015) Homepage. www.MODULUSHCA. com. Accessed 22 Jan 2015

5. MODULUSHCA (ed) (in print) Deliverable 2.1-framework for physical Internet embedded in interconnected FMCG logistics. Brussels

6. tenHompel M, Schmidt T, Nagel L (2007) Materialflusssysteme Förder- und Lagertechnik. Springer, Heidelberg

7. BVL (2015) Homepage. http://www.bvl.de/issl. Accessed 22 Jan 2015

8. Landschützer C, Jodin D, Ehrentraut F (2014) Modular boxes for the Physical Internet - technical aspects. In: Literature serieseconomics and logistics. International scientific symposium on logistics 7, Cologne, pp 191-234
9. Physical Internet Initiative (2015) Physical Internet mainfesto. http://physicalinternetinitiative.org/. Accessed 22 Jan 2015

10. Montreuil B, Meller RD, Ballot E (2010) Towards a Physical Internet: the impact on logistics facilities and material handling systems design and innovation. In: Gue $\mathrm{K}$ (ed) Progress in material handling research. Material Handling Industry of America, USA, pp 305-327

11. Meller RD, Lin YH, Ellis KP (2012a) The impact of standardized metric Physical Internet containers on the shipping volume of manufacturers. In: Proceedings of INCOM'12: 14th IFAC symposium on information control problems in manufacturing, Bucharest, 14/1, pp 364-371

12. Meller RD, Lin YH, Ellis KP (2012b) The impact of standardized Physical Internet containers on shipping volume. In: Proceedings of ILS 2012: 4th international conference on information systems, Logistics and Supply Chain. Quebec

13. Meller RD, Lin YH, Ellis KP, Thomas LM (2012) Standardizing container sizes saves space in the trailer. A result of the CELDi Physical Internet project. Center for Excellence in Logistics and Distribution. University of Arkansas

14. Moura A, Oliverira JF (2005) A GRASP approach to the container-loading problem. In: IEEE intelligent systems. IEEE Computer Society, 20/4, pp 50-57

15. Dyckhoff H (1990) A topology of cutting and packing problems. Eur J Oper Res 44(2):145-159

16. MODULUSHCA (ed) (2013) Deliverable 3.1-functional specification of iso modular logistics units in FMCG. Internal work paper, Brussels

17. Gehring H, Bortfeldt A (1997) A genetic algorithm for solving the container loading problem. Int Trans Oper Res 4(5/6):401-418

18. Takahara S (2005) Loading problem in multiple containers and pallets using strategic search method. In: Modeling decisions for artificial intelligence, proceedings lecture notes in artificial intelligence, vol 3558. Springer, Berlin, pp 448-456

19. Bischoff EE, Ratcliff MSW (1995) Issues in the development of approaches to container loading. Omega 23(4):377-390

20. Dowsland WB (1991) Three-dimensional packing: solution approaches and heuristic development. Int $\mathrm{J}$ Prod Res 29(8):1673-1685

21. Scheithauer G (1992) Algorithm for the container loading problem. In: Gaul W, Bachem A, Habenicht W, Runge W, Stahl WW (eds) Operational research proceedings. Springer, Berlin, pp 445-452

22. Chen CS, Lee SM, Shen QS (2006) An analytical model for the container loading problem. Eur J Oper Res 80(1):68-76

23. Wong TN, Chow PS, Sculli D (2006) A heuristic for sea-freight container selection, cargo allocation and cargo orientation. J Oper Res Soc 57(12):1452-1463

24. Xue J, Lai KK (1997) A study on cargo forwarding decisions. Comput Ind Eng 33(1-2):63-66

25. Mongeau M, Bes C (2003) Optimization of aircraft container loading. IEEE Trans Aerosp Electron Syst 39(1):140-150

26. Deutsches Institut für Normung - Normenausschuss Transportketten (ed) (1978) DIN ISO 3569 Stetigförderer; Klassifizierung von Stückgut. Beuth Verlag GmbH, Berlin

27. Deutsches Institut für Normung - Normenausschuss Verpackungswesen, Normenausschuss Papier und Pappe (eds) (2006) DIN 55405 Verpackung - Terminologie - Begriffe. Beuth Verlag $\mathrm{GmbH}$, Berlin

28. Deutsches Institut für Normung - Normenausschuss Transportketten (ed) (1989) DIN 30781 - Teil 1 - Beiblatt 1 Transportkette, Grundbegriffe, Erläuterungen. Beuth Verlag $\mathrm{GmbH}$, Berlin

29. MODULUSHCA (ed) (2014) Deliverable 3.2-modular logistics unit design. Brussels

30. Verein Deutscher Ingenieure (ed) (2004) VDI-Richtlinie 2700 Ladungssicherung auf Straßenfahrzeugen. Beuth Verlag GmbH, Berlin/Düsseldorf 
31. Verein Deutscher Ingenieure (ed) (2000) VDI-Richtlinie 2700 Blatt 4 - Ladungssicherung auf Straßenfahrzeugen Lastverteilungsplan. Beuth Verlag $\mathrm{GmbH}$, Berlin/Düsseldorf

32. Hauptverband der gewerblichen Berufsgenossenschaften (ed) (2006) BGR234: Lagereinrichtungen und Geräte, BG Regel. Germany

33. Stöhr T (2014) Optimierte Packordnung modularer Boxen. Master Thesis, Technical University of Graz

34. Martello S, Toth P (1990) Knapsack problems-algorithms and computer implementations. Wiley, New York

35. CubeMaster (2014) Hompage. http://www.cubemaster.net/Sub scription/home.asp. Accessed 22 Jan 2015

36. Verein Deutscher Ingenieure (ed) (1993) VDI 2221 - Methodik zum Entwickeln und Konstruieren technischer System und Produkte. Beuth Verlag GmbH, Berlin/Düsseldorf

37. Verein Deutscher Ingenieure (ed) (1997) VDI 2222 - Methodisches Entwickeln von Lösungsprinzipien. Beuth Verlag GmbH, Berlin/Düsseld
38. Verein Deutscher Ingenieure (ed) (2009) VDI 2209 - 3D-Produktmodellierung - Technische und organisatorische Voraussetzungen - Verfahren, Werkzeuge und Anwendungen - Wirtschaftlicher Einsatz in der Praxis. Beuth Verlag GmbH, Berlin/Düsseldorf

39. MODULUSHCA (ed) (in print) Deliverable 5.1-KPI and demonstration scenario for interconnected logistics. Brussels

40. Pahl G, Beitz W, Feldhousen J, Grote KH (2007) Konstruktionslehre. Springer, Berlin

41. Orloff MA (2007) Grundlagen der klassischen TRIZ - Ein praktisches Lehrbuch des erfinderischen Denkens für Ingenieure. Springer, Berlin

42. MODULUSHCA (ed) (in print) Deliverable 3.3-container prototyping. Brussels

43. Robotmech (2015) Homepage. https://www.robotmech.com/tech nologien.html. Accessed 22 Jan 2015

44. Verein Deutscher Ingenieure (ed) (1998) VDI-Richtlinie 2225 Blatt 3- Technisch-wirtschaftliches Konstruieren, Technisch-wirtschaftliche Bewertung. Beuth Verlag GmbH, Berlin/Düsseldorf 